\title{
Three new Leptographium spp. (Ophiostomatales) infecting hardwood trees in Norway and Poland
}

\author{
Robert Jankowiak (D) Agnieszka Ostafińska - Truls Aas • Halvor Solheim • \\ Piotr Bilański • Riikka Linnakoski • Georg Hausner
}

Received: 20 March 2018/ Accepted: 2 July 2018/Published online: 6 July 2018

(C) The Author(s) 2018

\begin{abstract}
Species of Leptographium are characterized by mononematous or synnematous conidiophores and are commonly associated with different arthropods. Some of them also produce a sexual state characterised by globose ascomata with elongated necks. Compared to investigations on coniferous trees, the occurrence of Leptographium species on hardwood trees has been poorly studied in Europe. During a survey of ophiostomatoid fungi on various hardwood tree species in Norway and Poland, three unusual
\end{abstract}

Electronic supplementary material The online version of this article (https://doi.org/10.1007/s10482-018-1123-8) contains supplementary material, which is available to authorized users.

R. Jankowiak $(\bowtie) \cdot$ A. Ostafińska

Department of Forest Pathology, Mycology and Tree

Physiology, Institute of Forest Ecosystem Protection,

University of Agriculture in Krakow, Al. 29 Listopada 46,

31-425 Kraków, Poland

e-mail: rljankow@cyf-kr.edu.pl

T. Aas $\cdot$ H. Solheim

Faculty of Environmental Sciences and Natural Resource

Management, Norwegian University of Life Sciences,

P.O. Box 5003, 1432 Ås, Norway

H. Solheim

Norwegian Institute of Bioeconomy Research,

P.O. Box 115, 1431 Ås, Norway species, which fit in the broader morphological description of Leptographium spp., were found in association with Trypodendron domesticum, Trypodendron signatum and Dryocoetes alni, and from wounds on a variety of hardwoods. Phylogenetic analyses of sequence data for six different loci (ITS1-5.8 S-ITS2, ITS2-LSU, ACT, $\beta$-tubulin, CAL, and TEF- $1 \alpha$ ) showed that these Leptographium species are phylogenetically closely related to the species of the Grosmannia olivacea complex. The first species forms a well-supported lineage that includes Ophiostoma brevicolle, while the two other new taxa resided in a separate lineage; possibly affiliated with Grosmannia francke-grosmanniae. All the new

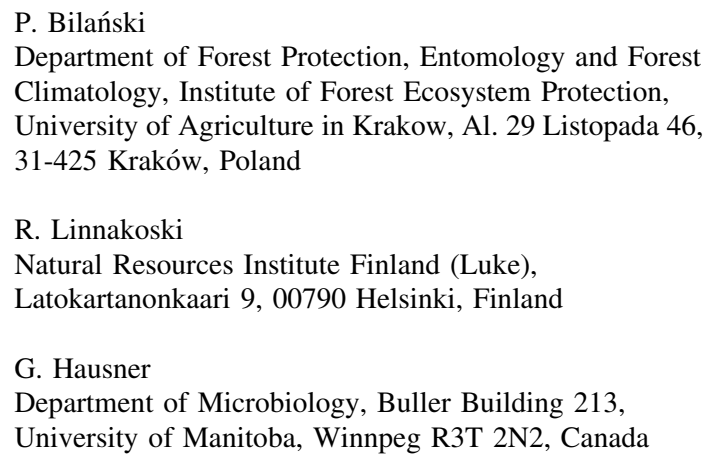


species produce perithecia with necks terminating in ostiolar hyphae and orange-section shaped ascospores with cucullate, gelatinous sheaths. These species also produce dark olivaceous mononematous asexual states in culture. In addition, two of the newly described species have a second type of conidiophore with a short and non-pigmented stipe. The new Leptographium species can be easily distinguished from each other by their appearance and growth in culture. Based on novel morphological characters and distinct DNA sequences, these fungi were recognised as new taxa for which the names Leptographium tardum sp. nov., Leptographium vulnerum sp. nov., and Leptographium flavum sp. nov. are provided.

Keywords Bark beetle-associated fungi . Leptographium flavum - Leptographium tardum . Leptographium vulnerum - Ophiostomatoid fungi . Phylogeny · Three novel species · Tree wound

\section{Introduction}

Species of Leptographium Lagerb. and Melin (Lagerberg et al. 1927) are commonly associated with bark beetles and weevils (Jacobs and Wingfield 2001). Most members are causal agents of blue stain of timber, having the potential to cause economic losses in the forestry industry (Jacobs et al. 2006). Some important tree diseases are also known, e.g. Leptographium wageneri complex species that is responsible for black stain root disease (BSRD) on conifers in western North America (Goheen and Cobb 1978).

In contrast to the conifers, occurrence of Leptographium spp. on hardwood trees has been relatively poorly investigated in Europe. Leptographium species have previously been isolated from the roots of various hardwood trees in the southeastern United States (Jacobs et al. 2006), and from beetles infesting hardwoods in China (Paciura et al. 2010). In Europe, Grosmannia francke-grosmanniae (R.W. Davidson) Zipfel, Z.W. de Beer and M.J. Wingf. was for a long time the only Leptographium/Grosmannia species reported from hardwoods (Davidson 1971; Jacobs and Wingfield 2001). Our recent research (Jankowiak et al. 2017) expanded the knowledge of hardwood-infecting Leptographium spp. in Europe by describing two new species of Leptographium that were assigned to the newly defined Grosmannia grandifoliae species complex.

In general, Leptographium spp. have mononematous, darkly pigmented conidiophores terminating in several series of branches giving rise to a brush-like conidiogenous structures that produce conidia in slimy masses, facilitating insect dispersal (Jacobs et al. 2001). However, species belonging to the Grosmannia olivacea complex form also synnematous conidiophores (De Beer and Wingfield 2013). In addition, some Leptographium species have a distinct welldeveloped sporothrix-like or hyalorhinocladiella-like synanamorphs (Jacobs and Wingfield 2001). Leptographium spp. also produce sexual states that have historically been classified in various genera including Grosmannia Goid. (Goidànich 1936), Ceratocystis Ellis and Halst. (Upadhyay 1981), and Ophiostoma Syd. and P. Syd. (Seifert et al. 1993). Zipfel et al. (2006) based on phylogenies derived from ribosomal large subunit (LSU) and beta-tubulin sequences, distinguished between Ophiostoma and Grosmannia, and redefined the latter genus to include all Leptographium spp. with sexual states.

Following the "one fungus one name" principles adopted in the Melbourne Code (Hawksworth 2011; Taylor 2011), De Beer and Wingfield (2013) reevaluated the taxonomy of Leptographium and Grosmannia, considering all available DNA sequence data for all species previously treated in either of the two genera. Ninety-four species were included and ten species complexes were defined within a broadly defined concept for Leptographium sensu lato, based on phylogenies resulting from analysing ribosomal internal transcribed spacer (ITS) and partial LSU sequences. The authors recognized that sequence data for additional gene regions would be necessary to fully resolve the delineation of Leptographium and Grosmannia, for which the type species Leptographium lundbergii and Grosmannia penicillata respectively, grouped in distinct species complexes. De Beer and Wingfield (2013) suggested that all known Leptographium and Grosmannia spp. placed in Leptographium s. $l$. based on phylogenetic inference, should be treated in their current genera (Leptographium or Grosmannia). However, new species, excluding those residing in the Genicillata complex, should provisionally be treated in Leptographium, irrespective of their sexual or asexual morphs. 
One of the species complexes recognized in Leptographium $s$. $l$. by De Beer and Wingfield (2013) was the Grosmannia olivacea complex. Earlier, Zipfel et al. (2006) transferred to Grosmannia spp., several species previously treated in the genus Pesotum (Okada et al. 1998) that also produced a sexual state. Massoumi Alamouti et al. (2007), Six et al. (2011) and Linnakoski et al. (2012) showed that additional species with synnematous asexual states also group within a monophyletic lineage along with G. olivacea. Currently, the G. olivacea complex is comprised of six species including G. olivacea (Math.Käärik) Zipfel, Z.W. De Beer and M.J. Wingf., G. sagmatospora (E.F. Wright and Cain) Zipfel, Z.W. De Beer and M.J. Wingf., G. olivaceapini (R.W. Davidson) Z.W. de Beer, Linnak. and M.J. Wingf., G. cucullata (H. Solheim) Zipfel, Z.W. De Beer and M.J. Wingf., G. davidsonii (Olechow. and J. Reid) Zipfel, Z.W. De Beer and M.J. Wingf., and G. vesca (R.W. Davidson) Zipfel, Z.W. De Beer and M.J. Wingf. The status of three other species, Graphium album (Corda) Sacc., G. francke-grosmanniae (R.W. Davidson) Zipfel, Z.W. De Beer and M.J. Wingf. and Ophiostoma brevicolle (R.W. Davidson) de Hoog and R.J. Scheff. is unclear. Based on previously published sequences and morphology data, these probably also belong to the G. olivacea complex (De Beer and Wingfield 2013). The species residing in this complex are well-characterised by sharing morphologically similar sexual and asexual states. They produce globose ascomata with cylindrical necks, terminating in prominent ostiolar hyphae on which sticky droplets containing orange-section shaped ascospores with cucullate gelatinous sheaths are formed (Mathiesen 1951; Davidson 1958, 1971; Wright and Cain1961; Olchowecki and Reid 1974; Solheim 1986). The asexual morphs are more variable, including the synnematous and mononematous asexual states with conidiogenous cells producing conidia showing annellations.

During a survey of ophiostomatoid fungi on hardwoods in Poland and Norway, three undescribed Leptographium species with a sexual state resembling species in the G. olivacea complex were isolated from different bark and ambrosia beetle species, as well as from tree wounds. The aim of this study was to identify the undescribed fungi and provide evidence to designate them as new taxa within Leptographium by comparing their morphology and DNA sequences with that of known species.

\section{Materials and methods}

Isolations, fungal isolates and herbarium specimens

Isolations were made from the beetles Trypodendron domesticum L., T. signatum Fabr. and Dryocoetes alni (Georg) in Norway, and T. domesticum and Anisandrus dispar (F.) in Poland. The adult beetles were excised from galleries established on decaying trees of Alnus incana (L.) (Norway), and on Fagus sylvatica L. and Quercus robur L. (Poland) with sterilised tweezers and stored individually in sterile $1.5 \mathrm{ml}$ Eppendorf tubes for later isolations. Isolations were also performed on active bleeding lesions of Carpinus betulus L., F. sylvatica and Q. robur in Poland (Figs. 1, 2). These stem lesions were most likely caused by frost damage. Samples were collected at seven localities in Poland during January-October 2011-2016 and from four localities during September 2015-September 2016 in Norway (Fig. 1).

Fungal isolations were made directly from beetles by crushing them onto the surface of $2 \%$ Malt Extract Agar (MEA) (20 g Biocorp malt extract, $20 \mathrm{~g}$ agar, $1000 \mathrm{~mL}$ distilled water), containing cycloheximide (200 mg, Aldrich-Sigma, St. Louis, Co. LLC.) and tetracycline sulphate (200 mg, Polfa, Tarchomin SA). The agar plates were subsequently incubated at $22{ }^{\circ} \mathrm{C}$ for 7-14 days and later examined for fungal growth. In Norway, each bark beetle was divided into three parts, elytra, head and the rest, before placing the parts in three different Petri dishes containing 2\% MEA without cycloheximide and tetracycline sulphate.

Fungal isolations were made from internal wood necrosis by sampling from cambium and wood within the range of the bleeding lesions up to a depth of $2 \mathrm{~mm}$. First the inner bark was excised with a sterile axe and small portions of discoloured tissue $(4 \times 4 \mathrm{~mm})$ were collected from the reaction zone of necrotised tissues with the aid of a sterile chisel, and plated on MEA with cycloheximide.

All fungal isolates used in this study are listed in Table 1. These isolates were maintained in the culture collection of the Department of Forest Pathology, Mycology and Tree Physiology; University of 


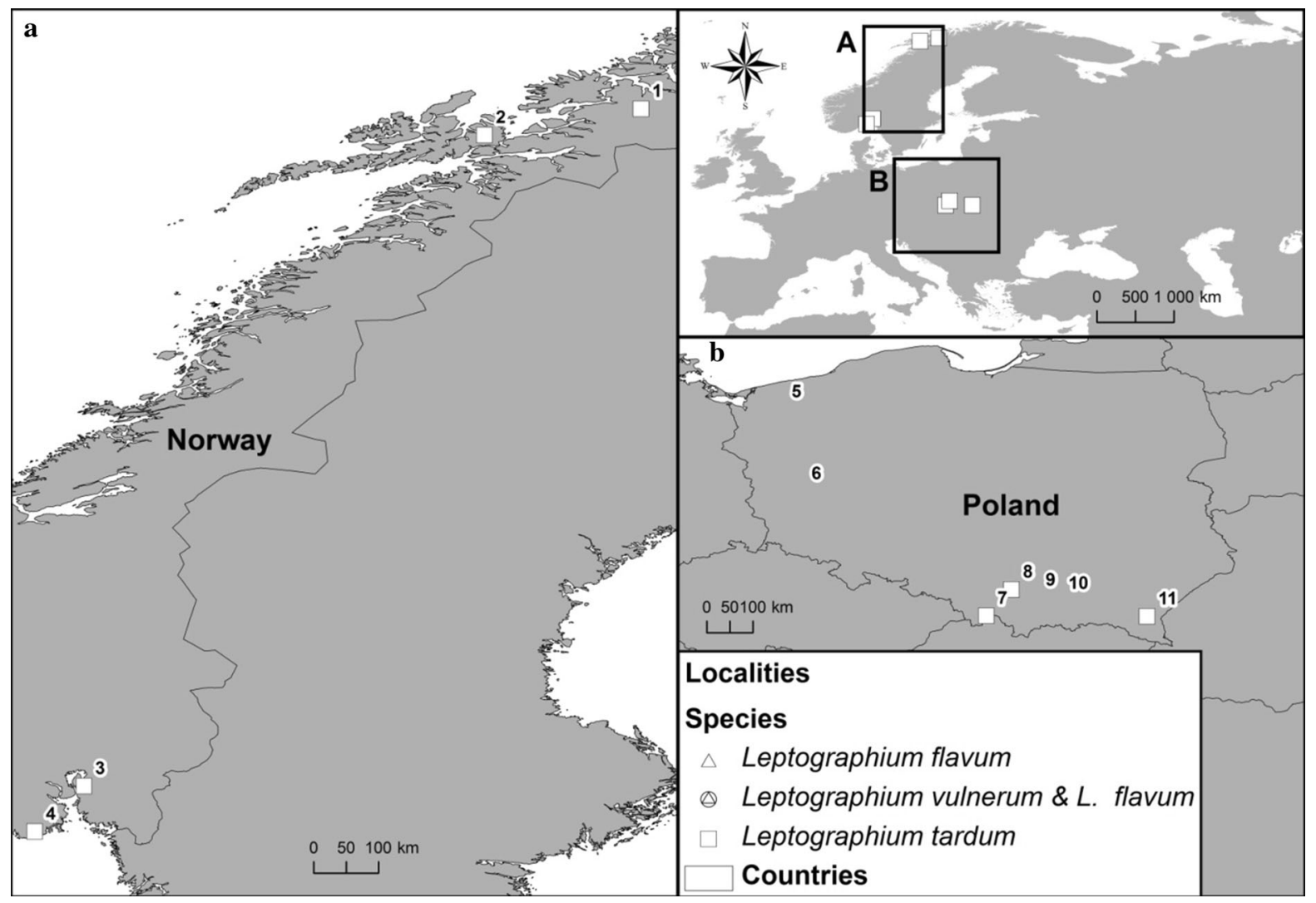

Fig. 1 Origin of isolates used in this study: 1-Bardufoss, Målselv, Norway $\left(69^{\circ} 4^{\prime} 5.54^{\prime \prime} \mathrm{N}, 18^{\circ} 28^{\prime} 46.01^{\prime \prime} \mathrm{E}\right) ; 2$-Rudda, Kvæfjord, Norway $\left(68^{\circ} 42^{\prime} 14.36^{\prime \prime} \mathrm{N}, 16^{\circ} 18^{\prime} 33.53^{\prime \prime} \mathrm{E}\right) ; 3-$ Syverud, Ås, Norway $\left(59^{\circ} 41^{\prime} 20.79^{\prime \prime} \mathrm{N}, 10^{\circ} 45^{\prime} 10.18^{\prime \prime} \mathrm{E}\right) ; 4$ Tagtvedt, Larvik, Norway $\left(59^{\circ} 3^{\prime} 37.00^{\prime \prime} \mathrm{N} 10^{\circ} 4^{\prime} 6.68^{\prime \prime}\right) \mathrm{E}$; 5Resko, Poland (53 $\left.45^{\prime} 56.18^{\prime \prime} \mathrm{N}, 15^{\circ} 25^{\prime} 19.25^{\prime \prime} \mathrm{E}\right)$; 6-Babimost,

Agriculture in Krakow, Poland. The Norwegian isolates are stored at the culture collection of the Norwegian Institute of Bioeconomy. Ex-type isolates of new species described in this study were deposited in the Westerdijk Fungal Biodiversity Institute (CBS), Utrecht, the Netherlands, and in the culture collection (CMW) of the Forestry and Agricultural Biotechnology Institute (FABI), University of Pretoria, South Africa. Type specimens were deposited in the Herbarium of the University of Turku, Finland (TUR), Finland. A culture of Ophiostoma brevicolle, which is closely related to Leptographium taxon 1 was sourced from the culture collection of University of Manitoba as WIN(M)811 (= CBS150.78) in Canada (Table 1). Taxonomic descriptions and nomenclatural data were registered in MycoBank (www.MycoBank.org) (Robert et al. 2013).
Poland $\left(52^{\circ} 10^{\prime} 23.42^{\prime \prime} \mathrm{N}, 15^{\circ} 48^{\prime} 37.38^{\prime \prime} \mathrm{E}\right)$; 7-Sopotnia, Poland $\left(49^{\circ} 35^{\prime} 39.54^{\prime \prime} \mathrm{N}, \quad 19^{\circ} 16^{\prime} 39.02^{\prime \prime} \mathrm{E}\right)$ 8-Zabierzów, Poland $\left(50^{\circ} 6^{\prime} 26.01^{\prime \prime} \mathrm{N}, \quad 19^{\circ} 46^{\prime} 11.71^{\prime \prime} \mathrm{E}\right) ; \quad 9-$ - Ispina, Poland $\left(50^{\circ} 6^{\prime} 20.61^{\prime \prime} \mathrm{N}, 20^{\circ} 22^{\prime} 11.85^{\prime \prime} \mathrm{E}\right)$; 10 -Wierzchosławice, Poland, $50^{\circ} 2^{\prime} 21.06^{\prime \prime} \mathrm{N}, \quad 20^{\circ} 48^{\prime} 49.32^{\prime \prime} \mathrm{E}, \quad 11$-Rozpucie, Poland $\left(49^{\circ} 34^{\prime} 59.71^{\prime \prime} \mathrm{N}, 22^{\circ} 24^{\prime} 19.38^{\prime \prime} \mathrm{E}\right)$

DNA extraction, PCR and sequencing

Fungal isolates were grown on $2 \%$ malt extract agar [MEA: $20 \mathrm{~g} \mathrm{Bacto}^{\mathrm{TM}}$ Malt Extract ${ }^{-1}, 20 \mathrm{~g} \mathrm{BBL}^{\mathrm{TM}} \mathrm{A}$ gar, Grade $\mathrm{A}^{-1}$ (Becton, Dickinson and Company Sparks, USA) and $1 \mathrm{~L}$ distilled water] in $60 \mathrm{~mm}$ plastic Petri dishes for 1-2 weeks prior to DNA extraction. DNA was extracted using the Genomic Mini AX Plant Kit (A\&A Biotechnology, Gdynia, Poland) according to the manufacturer's protocol.

Six loci were amplified for sequencing and phylogenetic analyses, including ITS1-5.8 S-ITS2, ITS2LSU, ACT, $\beta$ T, CAL and TEF 1- $\alpha$. The following primers were used: ITS 1-F (Gardes and Bruns 1993) and ITS4 (White et al. 1990) for ITS1-5.8 S-ITS2, ITS3 and LR3 (White et al. 1990) for ITS2-LSU, Lepact-F and Lepact-R (Lim et al. 2004) for ACT, 


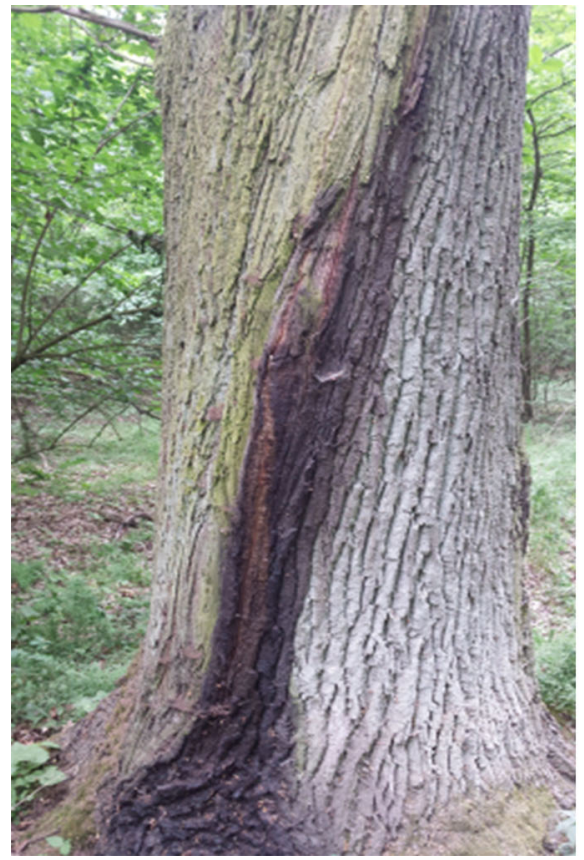

Fig. 2 Active bleeding lesions on oak stems (Ispina study site)

Bt2a and Bt2b (Glass and Donaldson 1995) plus T10 (O'Donnell and Cigelnik 1997) for $\beta T$, CL2F and CL2R (Duong et al. 2012) for CAL, and EF1-F and EF2-R (Jacobs et al. 2004) for TEF 1- $\alpha$.

Amplification of the gene regions was performed under the following conditions: a denaturation step at $98{ }^{\circ} \mathrm{C}$ for $30 \mathrm{~s}$ followed by 35 cycles of $5 \mathrm{~s}$ at $98^{\circ} \mathrm{C}$, $10 \mathrm{~s}$ at $52-64{ }^{\circ} \mathrm{C}$ (depending on the type of primer and fungal species) and $30 \mathrm{~s}$ at $72{ }^{\circ} \mathrm{C}$, and a final elongation step at $72{ }^{\circ} \mathrm{C}$ for $8 \mathrm{~min}$. Gene fragments were amplified in a $25 \mu \mathrm{L}$ reaction mixture containing $0.25 \mu \mathrm{L}$ of Phusion High-Fidelity DNA polymerase (Finnzymes, Espoo, Finland), $5 \mu \mathrm{L}$ Phusion HF buffer $(5 \times), 0.5 \mu \mathrm{L}$ of dNTPs $(10 \mathrm{mM}), 0.75 \mu \mathrm{L}$ DMSO $(100 \%)$ and $0.5 \mu \mathrm{L}$ of each primer $(25 \mu \mathrm{M})$. Amplification reactions were performed in the LabCycler Gradient (Sensoquest Biomedical Electronics GmbH, Germany). The PCR products were visualized under UV light on a $2 \%$ agarose gel stained with Midori Green DNA Stain (Nippon Genetic Europe).

Amplified products were sequenced with the BigDye $^{\circledR}$ Terminator v 3.1 Cycle Sequencing Kit (AB Applied Biosystems, Foster City, CA, USA) and ABI PRISM 3100 Genetic Analyzer (Applied Biosystems, Foster City, USA), at the DNA Research Centre (Poznań, Poland) using the same primers that were

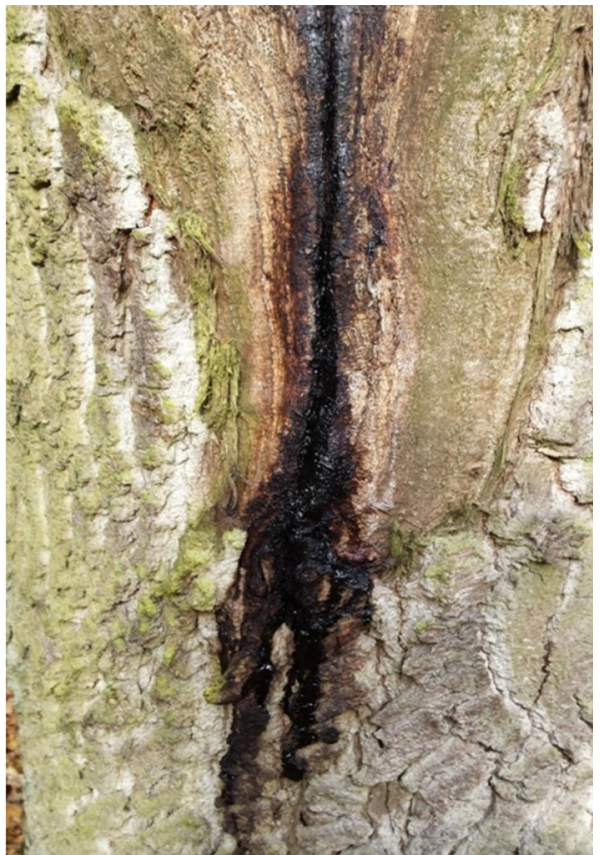

used for the PCR. The sequences (Table 1) were deposited in NCBI GenBank and compared with sequences in GenBank using the BLASTn algorithm.

Sequence analyses

BLAST searches using the BLASTn algorithm were performed to retrieve similar sequences from GenBank (http://www.ncbi.nlm.nih.gov). Accession numbers of these sequences are presented in the corresponding phylogenetic trees (Figs. 3, 4, 5, 6, 7, 8). Newly obtained sequences were deposited in GenBank and their accession numbers are presented in Table 1.

Individual data sets for the ITS1-5.8 S-ITS2, ITS2LSU, ACT, $\beta$ T, CAL, and TEF1- $\alpha$ gene regions were used for phylogenetic analyses. Data sets were compiled and edited with programs implemented within the Molecular Evolutionary Genetic Analysis (MEGA) v6.06 software (Tamura et al. 2013). The ITS2-LSU sequences obtained from isolates of our newly described Leptographium species (Table 1) were compared with those of 75 other Leptographium s. $l$. species. The later sequences were obtained from GenBank and allowed for inferring the phylogenetic position of these new species within the genus. In 


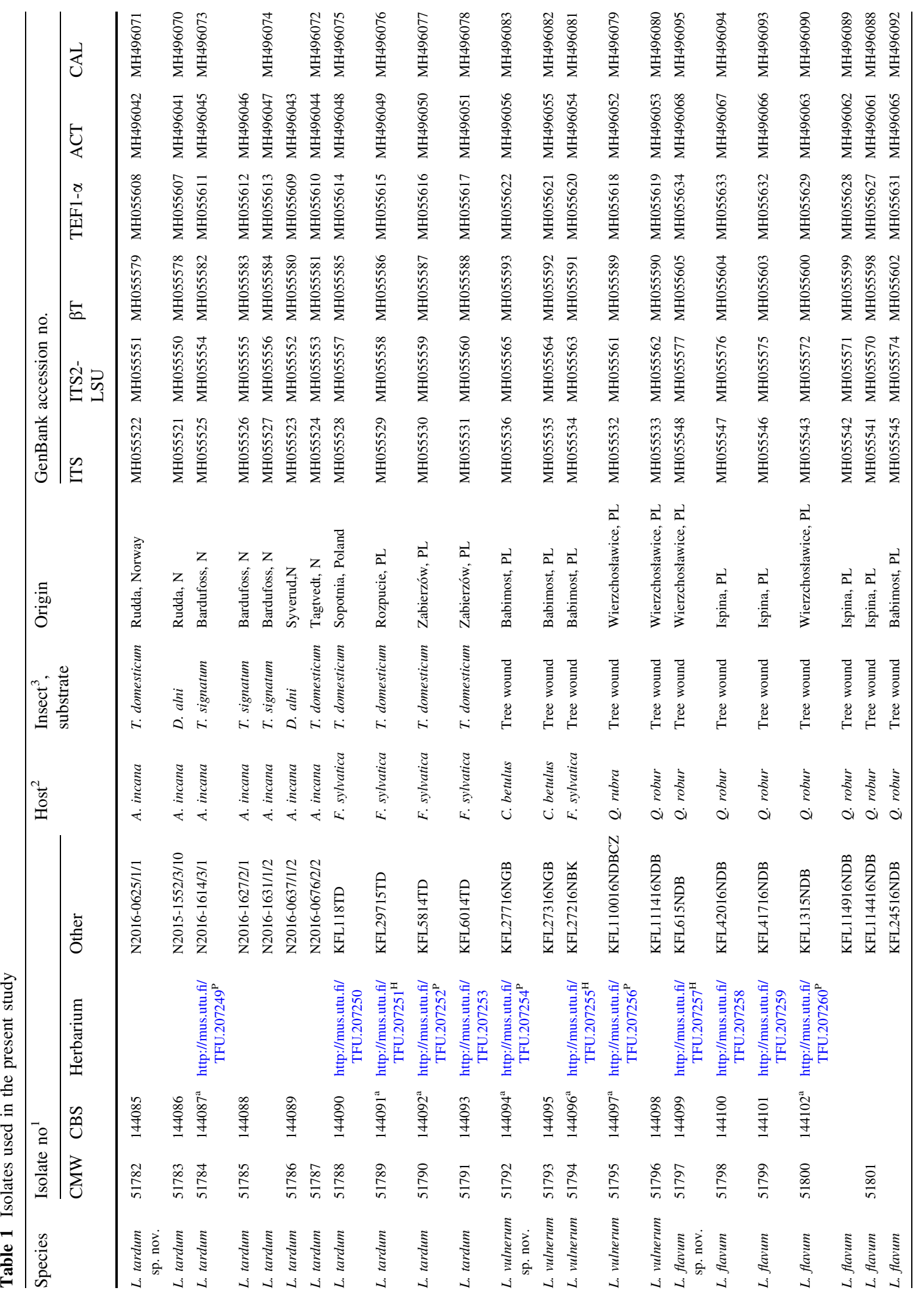




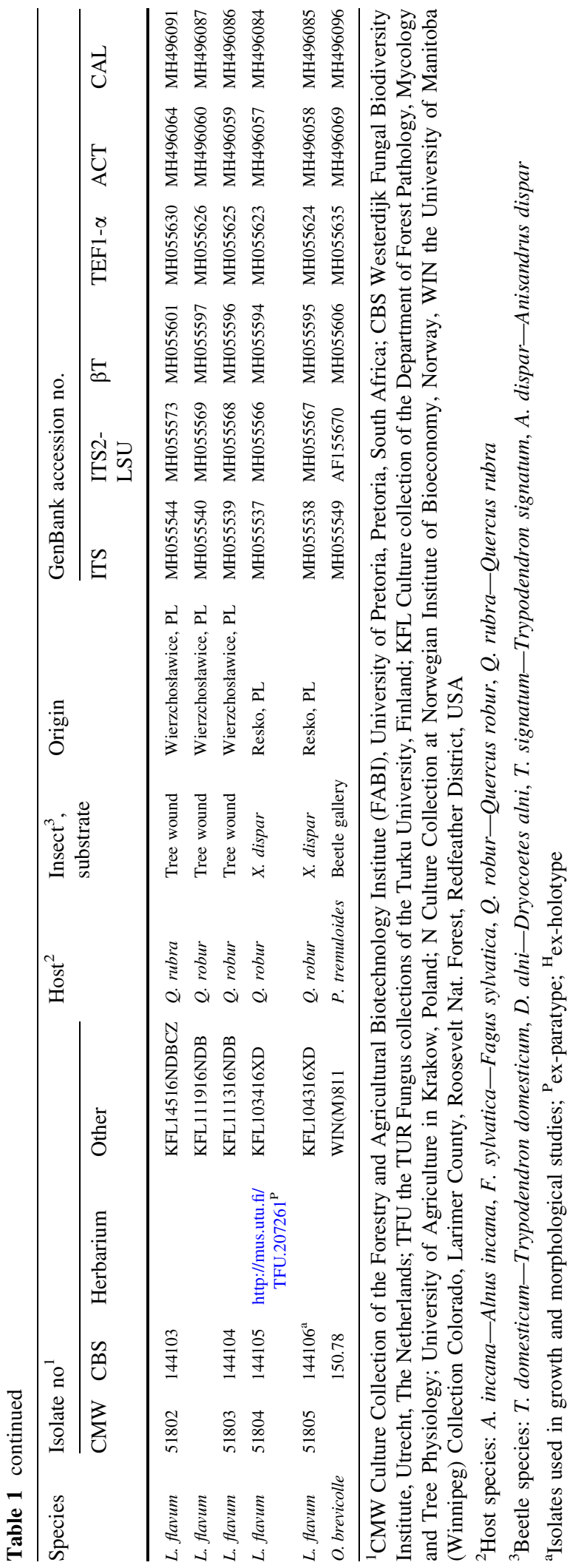




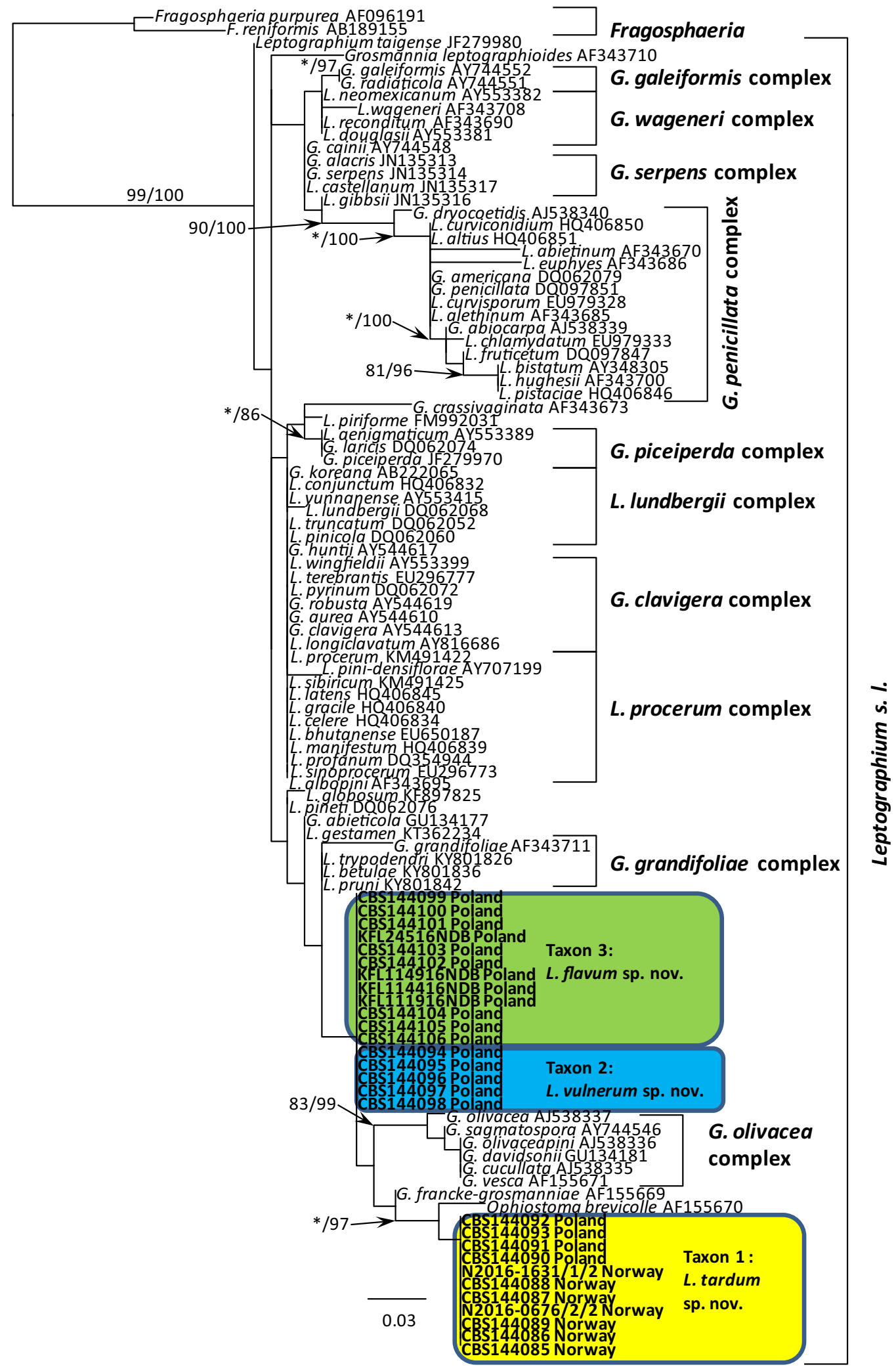


4Fig. 3 Phylogram obtained from Maximum Likelihood (ML) analyses of the LSU region showing the placement of isolates obtained from Poland and Norway in Leptographium s. $l$. Sequences obtained during this study are presented in bold type. Bootstrap values $>75 \%$ for ML and posterior probabilities $>75 \%$ obtained from Bayesian (BI) analyses are indicated at the nodes as follows: ML/BI. *Bootstrap values $<75 \%$. The tree is drawn to scale with branch length measured in the number of substitutions per site

addition the ITS1-5.8 S-ITS2 and four protein coding gene regions (ACT, $\beta \mathrm{T}, \mathrm{CAL}, \mathrm{TEF} 1-\alpha$ ) for 28 isolates (Table 1) were sequenced to enhance the delineation of closely related species.

Sequence alignments were performed using the online version of MAFFT v7 (Katoh and Standley 2013). The ITS, LSU, ACT, $\beta$ T, CAL and TEF- $1 \alpha$ data sets were aligned using the E-INS-i strategy with a 200PAM $/ \kappa=2$ scoring matrix, a gap opening penalty of 1.53 and an offset value of 0.00 . Aligned data sets of the protein-coding genes were compared to gene maps constructed by Yin et al. (2015) to determine the presence or absence of introns and confirm that introns and exons were appropriately aligned (Tables S1-S4).

Phylogenetic analyses were performed for each of the data sets using two different methods: maximum likelihood (ML) and Bayesian inference (BI). For ML and Bayesian analyses, the best-fit substitution models for each data set were established using the corrected Akaike Information Criterion (AICc) in jModelTest 2.1.10 (Guindon and Gascuel 2003; Darriba et al. 2012). Maximum likelihood (ML) analyses were conducted with PhyML 3.0 (Guindon et al. 2010), via the Montpelier online server (http://www.atgcmontpellier.fr/phyml/) with 1000 bootstrap replicates. BI analyses based on a Markov Chain Monte Carlo (MCMC) were carried out with MrBayes v3.1.2 (Ronquist and Huelsenbeck 2003). The MCMC chains were run for 10 million generations using the best-fit model. Trees were sampled every 100 generations, resulting in 100,000 trees from both runs. The burn-in value for each dataset was determined in Tracer v1.4.1 (Rambaut and Drummond 2007). The remaining trees were utilized to generate a majority rule consensus tree for determining the posterior probability values.
Morphological characterization

Morphological observations were made for selected isolates and herbarium specimens chosen to represent the type specimens. Cultures were grown on $2 \%$ MEA with or without host tree twigs to induce potential ascocarp formation. The autoclaved twigs with bark were placed in the middle of the agar plates. Fungal cultures were grown starting with a single spore, and crossings were made for all isolates following the technique described by Grobbelaar et al. (2010). Cultures were incubated at $25^{\circ} \mathrm{C}$ for $14-21$ days and inspected frequently for the formation of fruiting structures.

Morphological characteristics were examined by mounting the sexual and asexual fruiting structures in $80 \%$ lactic acid on glass slides, and these were observed using a Nikon Eclipse $50 i$ microscope (Nikon ${ }^{\circledR}$ Corporation, Tokyo, Japan) with an Invenio 5S digital camera (DeltaPix ${ }^{\circledR}$, Maalov, Denmark) to capture photographic images. Microscopy was done as described by Kamgan Nkuekam et al. (2011a, b). Colours were described with the charts of Kornerup and Wanscher (1978).

Fifty measurements were made for each significant taxonomically relevant structure whenever possible, with the Coolview 1.6.0 software (Precoptic ${ }^{\circledR}$, Warsaw, Poland). Averages, ranges and standard deviations were computed for the measurements, and these are presented in the format '(min-max) (mean-SD)'.

Culture characteristics

Growth characteristics for the three newly described species (Taxon 1 to 3) were determined by analysing the radial growth for four representative isolates of each of the studied species (Table 1). Agar disks $5 \mathrm{~mm}$ diam. were cut from actively growing margins of colonies of each isolate to be tested, and placed at the center of plates containing 2\% MEA. Four plates for each isolate were incubated at the following temperatures: $5,10,15,20,25,30$ and $35{ }^{\circ} \mathrm{C}$. Colony diameters (three measurements per plate) were determined 7 and $14 \mathrm{~d}$ after inoculation and growth rates were calculated as $\mathrm{mm} / \mathrm{d}$. 


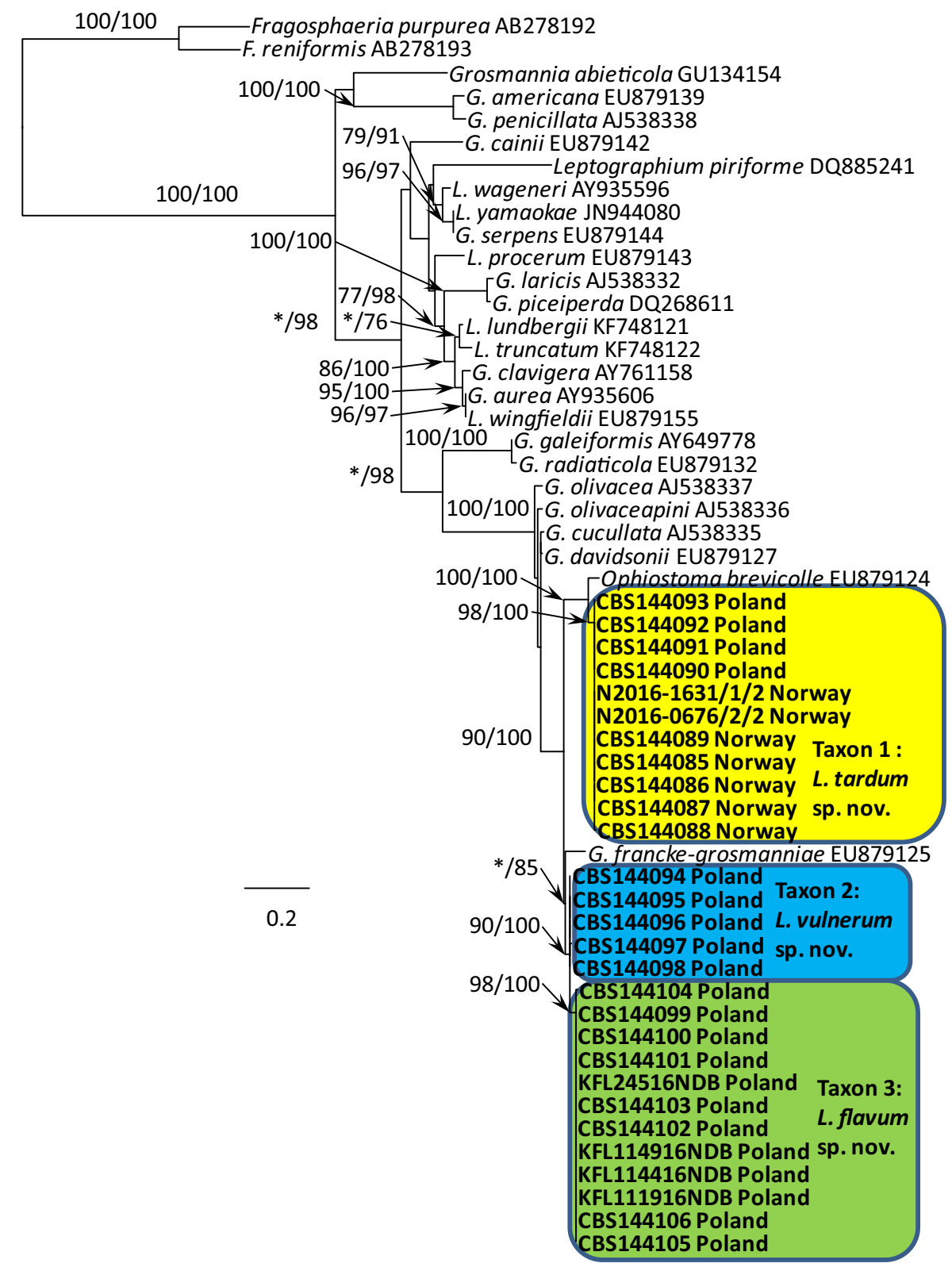

Fig. 4 Phylogram obtained from ML analyses of the ITS1-5.8 S-ITS2 region showing the placement of isolates obtained from Poland and Norway in Leptographium s. $l$. Sequences obtained during this study are presented in bold type. Bootstrap values $>75 \%$ for $\mathrm{ML}$ and posterior probabilities $>75 \%$

\section{Results}

Morphological characteristics

Isolates of the three new taxa emerging from this study were dissimilar in growth and culture morphology. obtained from Bayesian (BI) analyses are presented at the nodes as follows: ML/BI. *Bootstrap values $<75 \%$. The tree is drawn to scale with branch length measured in the number of substitutions per site

Colonies for Taxon 1 displayed a rusty-yellowish colour; whereas Taxon 2 colonies had a greyish appearance and those of Taxon 3 were deep yellowish. The growth of the three new taxa on MEA was also different, with Taxon 1 being the slowest and Taxon 2 being the fastest. The optimal growth temperature was 


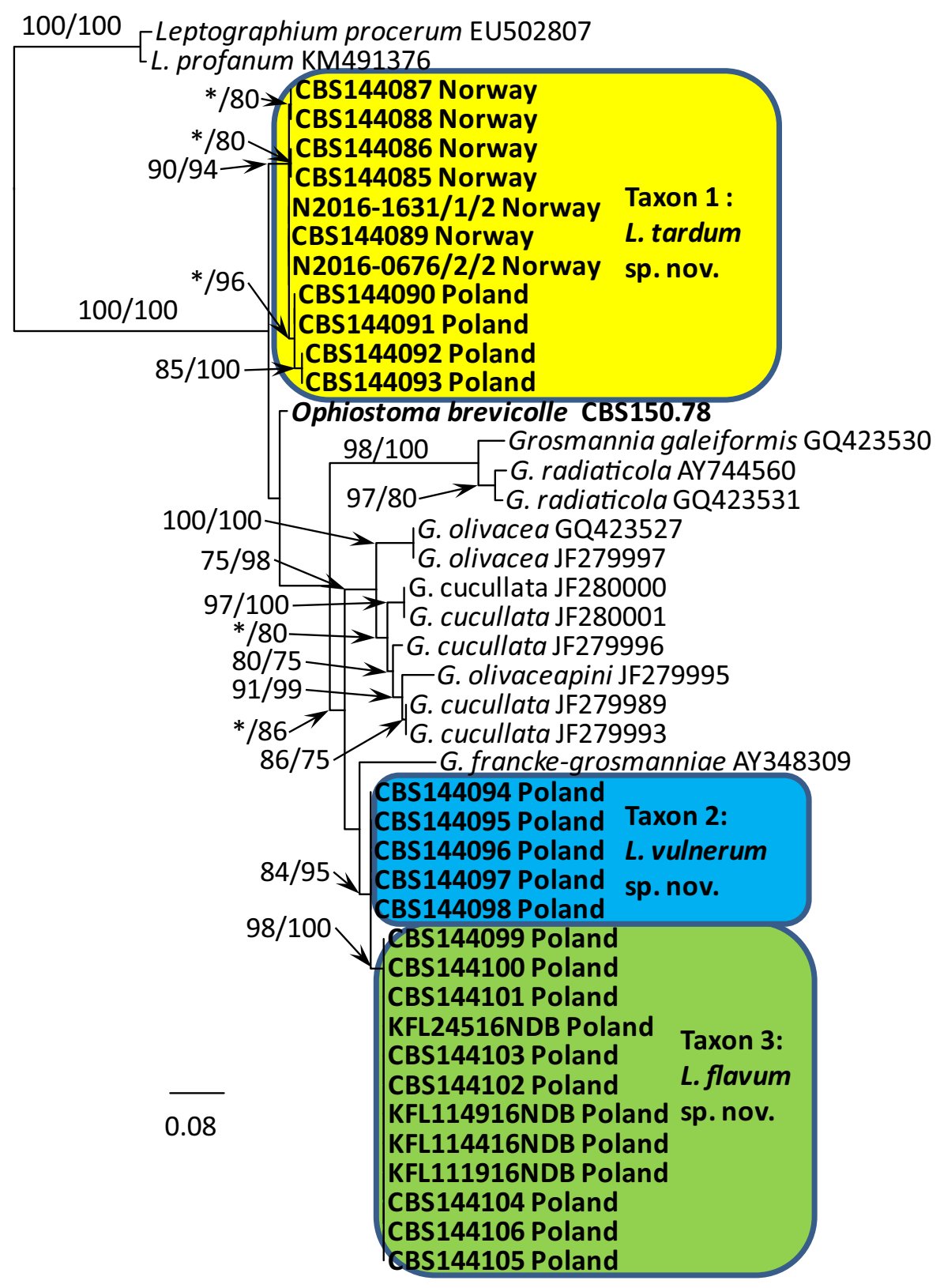

Fig. 5 Phylogram obtained from the analysis of $\beta$ T sequences for members of Leptographium s. l. showing the phylogenetic relationships of the Polish and Norwegian isolates collected during this study. Sequences obtained during this study are presented in bold type. The phylogram was obtained from Maximum Likelihood (ML) analyses. Bootstrap values $>75 \%$

$25{ }^{\circ} \mathrm{C}$ for isolates of Taxon 1 and $20{ }^{\circ} \mathrm{C}$ for isolates of Taxon 2 and Taxon 3. For all new taxa examined the mononematous conidiophores with dark olivaceous stipes were common and hyphae were superficial on the agar. Taxon 2 and Taxon 3 produced shorter for ML and posterior probabilities $>75 \%$ obtained from Bayesian (BI) analyses are presented at the nodes as follows: ML/BI. *Bootstrap values $<75 \%$. The tree is drawn to scale with branch length measured in the number of substitutions per site

mononematous conidiophores with light olivaceous stipes. The dimensions of most morphological structures were similar and partly overlapped among species in this complex. The droplets containing conidia, appeared initially hyaline, but turned 


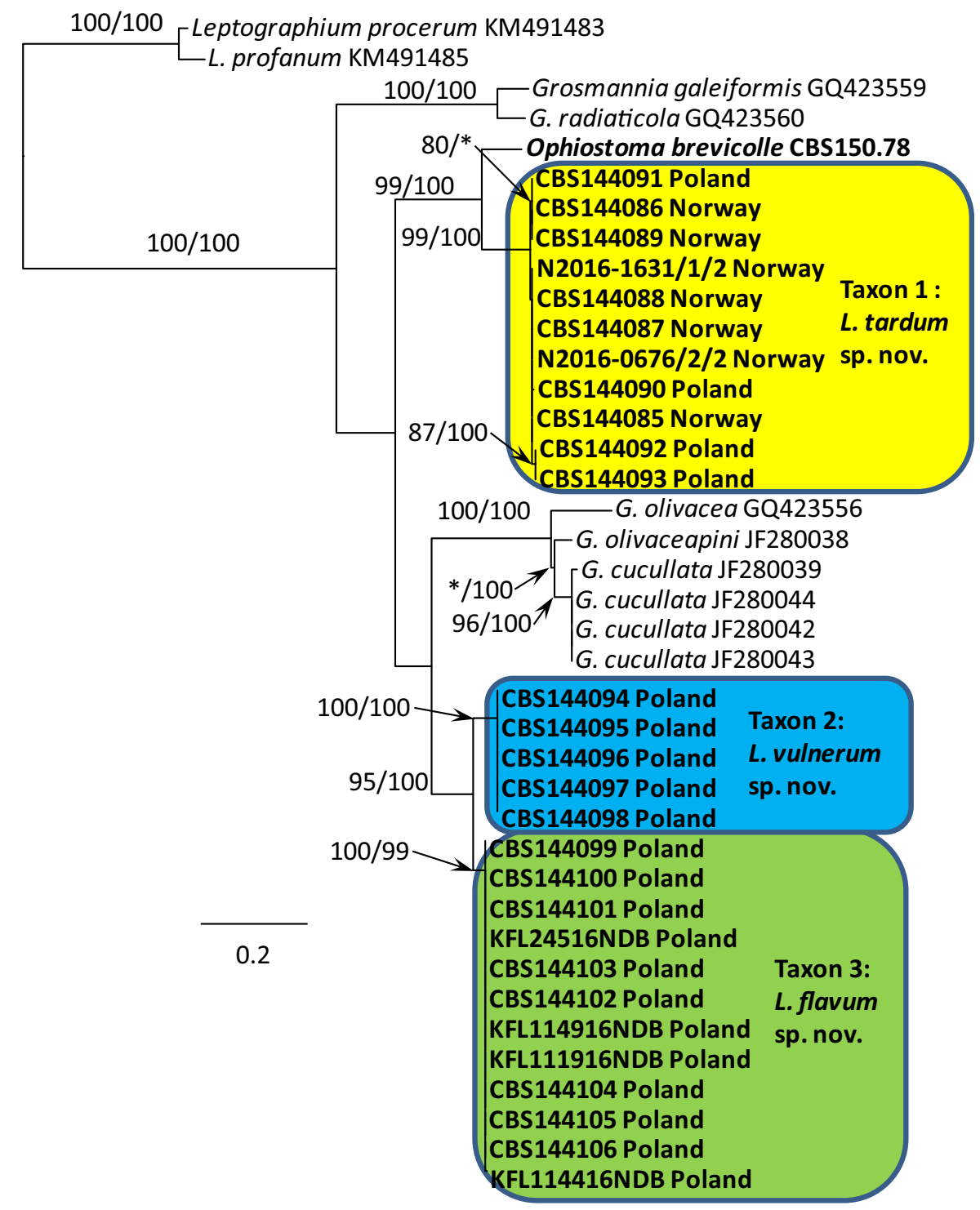

Fig. 6 Phylogram obtained from the analysis of TEF1- $\alpha$ sequences for members of Leptographium s. l. showing possible placements for the Polish and Norwegian isolates examined in this study. Sequences obtained during this study are presented in bold type. The phylogram was obtained from Maximum

whitish-yellowish with age. A sexual state could be induced in all isolates, the most distinct feature observed in both the herbarium specimens and the studied isolates were the pale brown, straight and sharply pointed ostiolar hyphae and orange-section shaped ascospores with cucullate gelatinous sheaths. Isolates derived from single spores for all three new taxa produced ascomata in culture, suggesting that they are homothallic. Morphological differences that
Likelihood (ML) analyses. Bootstrap values $>75 \%$ for ML and posterior probabilities $>75 \%$ obtained from Bayesian (BI) analyses are presented at nodes as follows: ML/BI. *Bootstrap values $<75 \%$. The tree is drawn to scale with branch length measured in the number of substitutions per site

distinguish the three newly described species are discussed in the Notes within the Taxonomy section.

DNA sequence analyses

The amplified DNA fragments were 563-655 bp long for the ITS1-5.8 S-ITS2 region, 936-971 bp long for the 5.8S-ITS2-LSU region, 308-437 bp long for the partial $\beta T, 812-861$ bp long for the TEF1- $\alpha$ segment, 


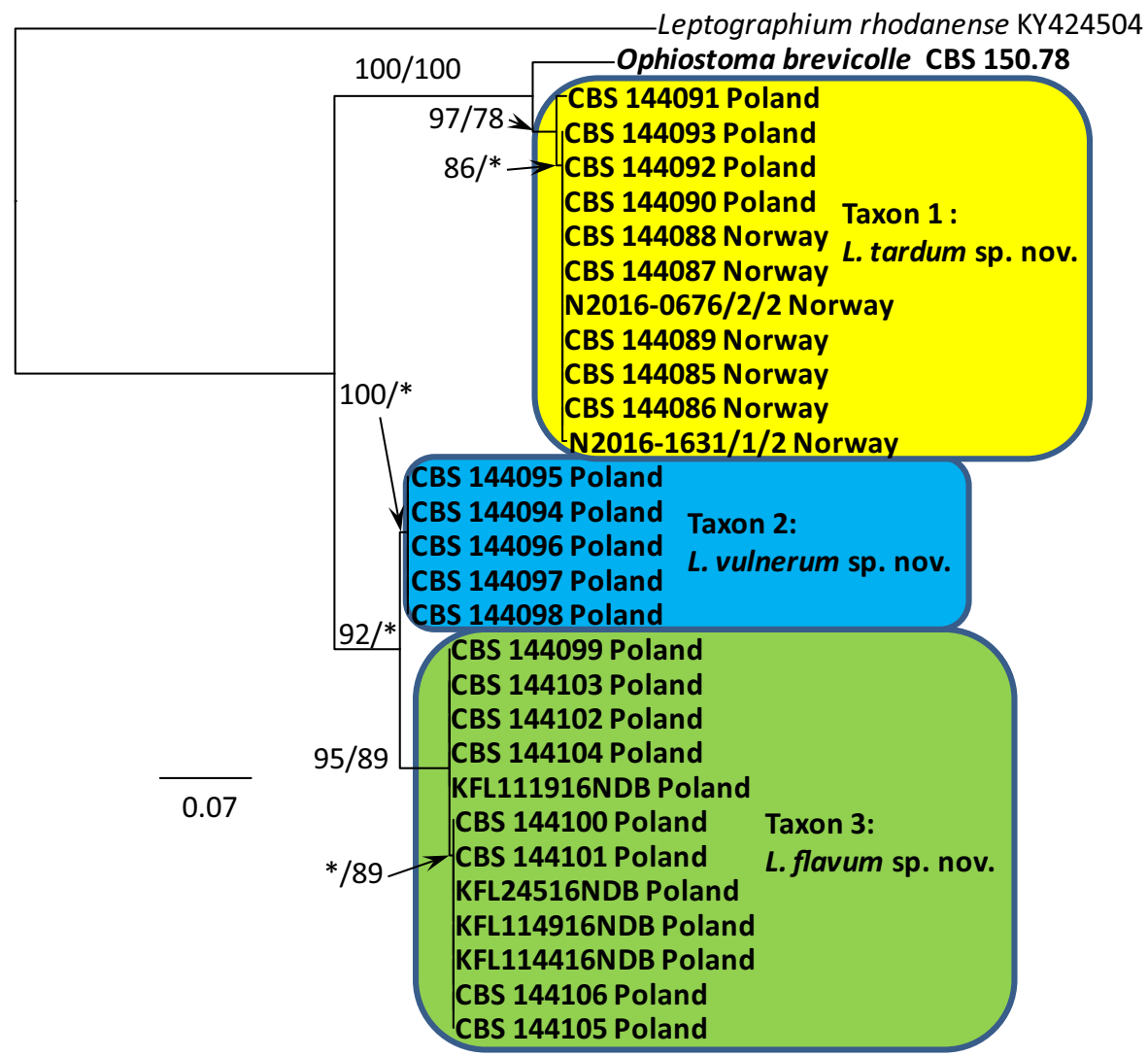

Fig. 7 Phylogram obtained from the analysis of ACT sequences for members of Leptographium s. l. showing possible placements for the Polish and Norwegian isolates examined in this study. Sequences obtained during this study are presented in bold type. The phylogram was obtained from Maximum

835-884 bp long for the partial ACT and 500-544 bp long for the partial CAL. The aligned data set for the ITS1-5.8S-ITS2 region included 105 taxa and 652 characters (with gaps). The aligned data set for the LSU gene region included 105 taxa and 334 characters (with gaps). The $\beta$ T data set consisted of 43 taxa and 380 characters (with gaps), and included the partial sequences for exon $3 / 4$, intron 4 and partial sequences for exon 5/6. The TEF- $1 \alpha$ data set consisted of 39 taxa and 811 characters (with gaps), including partial sequences for exon 4, all of intron 4, exon 5, intron 5, and partial sequences for exon 6. The ACT data set consisted of 30 taxa and 816 characters (with gaps), and included the partial sequences for exon 5 , intron 5 and partial sequences for exon 6 . The CAL data set consisted of 28 taxa and 634 characters (with gaps), including partial sequences for exon 3 , all of intron 3 , exon 4 , intron 4 , exon $5 / 6$, and partial sequences for
Likelihood (ML) analyses. Bootstrap values $>75 \%$ for ML and posterior probabilities $>75 \%$ obtained from Bayesian (BI) analyses are presented at nodes as follows: ML/BI. *Bootstrap values $<75 \%$. The tree is drawn to scale with branch length measured in the number of substitutions per site

intron 6. The BI and ML analyses for each data set produced trees with similar topologies (Figs. 3-8). The best-fitting substitution models selected for ML/ $\mathrm{BI}$ analyses were GTR + I+G, HKY + I, HKY + G, $\mathrm{HKY}+\mathrm{G}, \mathrm{GTR}+\mathrm{I}+\mathrm{G}$ and GTR $+\mathrm{I}$ for respectively the ITS, LSU, $\beta$ T, TEF- $1 \alpha$, ACT and CAL data sets.

The phylogenetic trees arising from the analyses of the LSU data for members of Leptographium s. $l$. showed sequences representing the G. olivacea complex being positioned between sequences that represent Taxon 1 and Taxa 2-3 with some nodes receiving statistical support (Fig. 3). In the LSU tree, 11 isolates of Taxon 1 originating from Norway and Poland formed a clade that included the sequence of the extype isolate of $O$. brevicolle, while 17 isolates of Taxon 2 and Taxon 3 resided in a separate clade. However, the LSU data did not distinguish clearly 


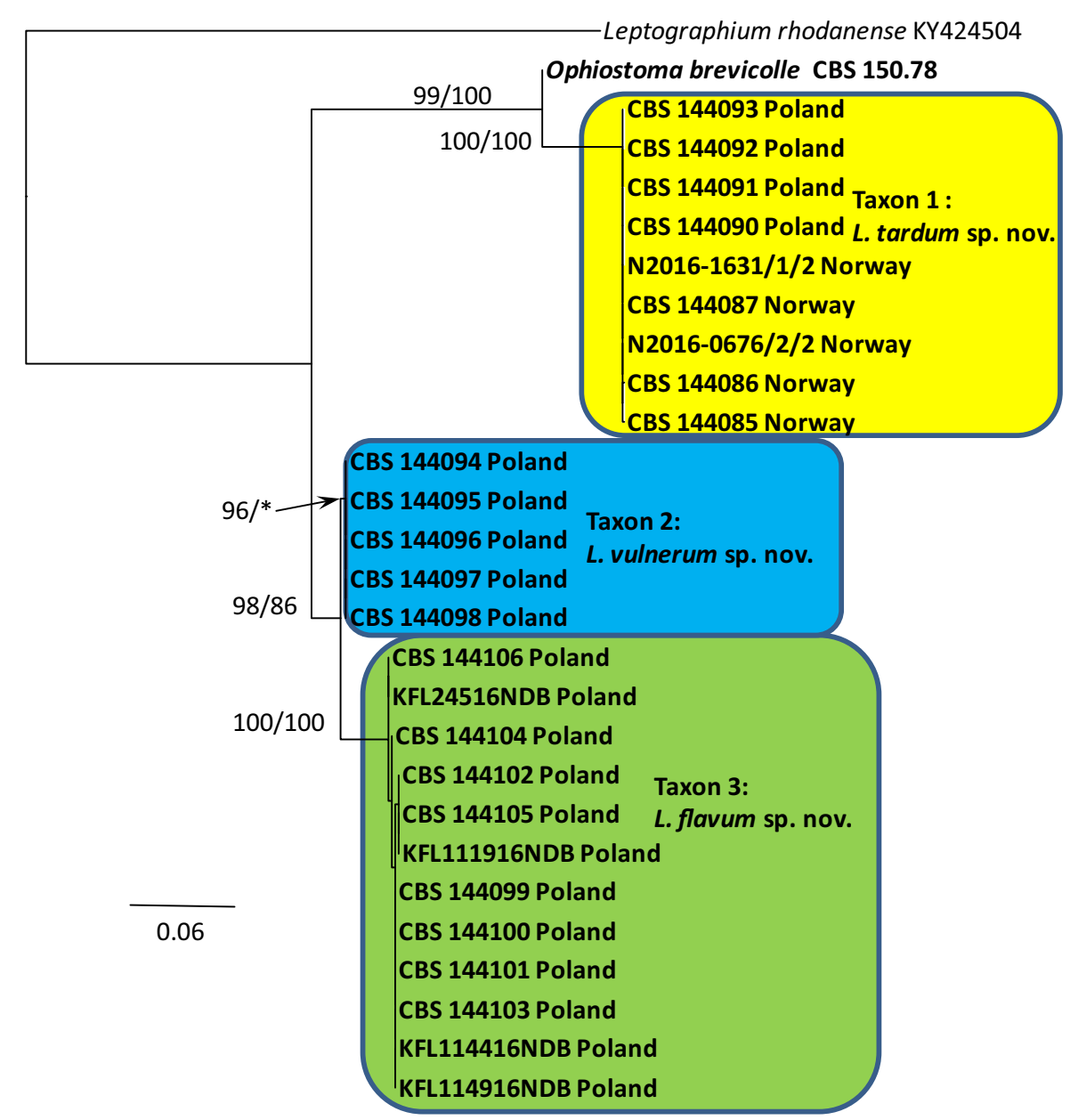

Fig. 8 Phylogram obtained from the analysis of CAL sequences for members of Leptographium s. l. showing possible placements for the Polish and Norwegian isolates examined in this study. Sequences obtained during this study are presented in bold type. The phylogram was obtained from Maximum

between members of Taxon 2 and Taxon 3. The LSU sequence for $G$. francke-grosmanniae branched basal to $O$. brevicolle and therefore outside of the $G$. olivacea species complex (Fig. 3).

ITS sequences obtained for our isolates when compared with sequences obtained from GenBank and reference isolates (Fig. 4) confirmed that our isolates could be assigned into three distinct taxa that are positioned adjacent to the G. olivacea species complex. Phylogenetic analysis of the ITS sequences showed that Taxon 1 is closely related to $O$. brevicolle while Taxon 2 and Taxon 3 appear to be more closely affiliated with $G$. francke-grosmanniae. Unlike the LSU sequences, the ITS data provides some
Likelihood (ML) analyses. Bootstrap values $>75 \%$ for $\mathrm{ML}$ and posterior probabilities $>75 \%$ obtained from Bayesian (BI) analyses are presented at nodes as follows: ML/BI. *Bootstrap values $<75 \%$. The tree is drawn to scale with branch length measured in the number of substitutions per site

differentiation between isolates of Taxon 2 and Taxon 3 (Fig. 4).

In the $\beta$-tubulin tree (Fig. 5), isolates of Taxon 1 grouped within a well-supported distinct lineage adjacent to the species that represent the G. olivacea complex and $O$. brevicolle. Intraspecific sequence variation of the $B \mathrm{~T}$ gene was found within this taxon, especially between the Norwegian and Polish isolates. Intraspecific variability detected for members of Taxon 1 ranged up to a maximum of 5 nucleotide positions (Table S1). A second group of isolates representing Taxon 2 and Taxon 3 grouped with $G$. francke-grosmanniae in the B-tubulin based phylogenetic tree (Fig. 5), but differed in length by 38 and 
$41 \mathrm{bp}$ nucleotide positions from that species. Analyses of the partial $\beta T$ gene also distinguished clearly between members comprising Taxon 2 versus members of Taxon 3 (Fig. 5).

The phylogram based on the TEF- $1 \alpha$ data confirmed that Taxon 1 and Taxa 2-3 form two wellsupported monophyletic lineages adjacent to the species that represent the $G$. olivacea complex (Fig. 6). Minor intraspecific sequence variation was found, but only among isolates of Taxon 1, up to a maximum of 5 positions (Table S2).

The phylogram obtained from for the ACT gene region showed differences between Taxa 1-3 and $O$. brevicolle (Fig. 7). Minor intraspecific sequence variation was found among isolates of Taxon 1 (up to a maximum of 4 positions, Table S3) and Taxon 3 (up to a maximum of 1 position, Table S3).

In the CAL tree (Fig. 8), isolates of Taxa 1-3 and O. brevicolle grouped into four well-supported distinct lineages. Intraspecific variability was detected only for members of Taxon 3 which ranged up to a maximum of 10 nucleotide positions (Table S4).

\section{Taxonomy}

Based on DNA sequences and morphological differences, Taxon 1 with isolates from Poland and Norway, and Taxa 2 and 3 from Poland could be distinguished from other Leptographium species, and are thus described here as new species.

\section{Taxon 1}

Leptographium tardum T. Aas, H. Solheim and R. Jankowiak, sp. nov. (Fig. 9) MycoBank: 826759.

Etymology Name refers to the very slow growth of this fungus on malt agar.

Sexual state develops on malt agar in 21 days. Perithecia superficial on wood and agar, bases light brown to dark brown, globose, unornamented, 100-238 (mean $163.7 \pm 23.8$ ) $\mu \mathrm{m}$ in diameter, necks dark brown, cylindrical, straight, 122-314.8 (mean $196.1 \pm 31.6) \mu \mathrm{m}$ long (including ostiolar hyphae), 23.3-46.9 (mean $33.9 \pm 5.5) \mu \mathrm{m}$ wide at base, 25.8-42.4 (mean $34 \pm 4.7$ ) $\mu \mathrm{m}$ wide at the tip (Fig. 9a, b). Ostiolar hyphae present, pale brown, straight, septate, numerous, divergent, tapering at the tip, up to $151.6 \mu \mathrm{m}$ long (Fig. 9c). Asci not seen.
Ascospores (Fig. 9d) one-celled, hyaline, orange section shaped in side view, ellipsoidal in face view, globose in end view, 4.3-5.9 (mean $5.1 \pm 0.41) \times$ 2.3-4.6 (mean $3.2 \pm 0.49$ ) $\mu \mathrm{m}$ including hyaline gelatinous sheath, $0.1-1 \mu \mathrm{m}$ thick.

Conidiophores macronematous, arising directly from hyphae, single solitary, without rhizoidal hyphae at the bases but often from the base emerged new conidiophores in different directions, 107.5-209.2 (mean $161.5 \pm 19.8$ ) $\mu \mathrm{m}$ in length (Figs. 9e, f). Stipes erect, olivaceous, 3-9 septate, 76.3-150.5 (mean $106.5 \pm 19.2) \mu \mathrm{m}$ long (from first basal septum to below primary branches), 4.4-7.8 (mean 5.6 \pm 0.7 ) $\mu \mathrm{m}$ wide below primary branches, apical cell not swollen, 5.4-8.2 (mean $6.7 \pm 0.7$ ) $\mu$ m wide at base, basal cell not swollen. Asexual state: Conidiogenous apparatus 39.6-68.9 (mean $51.1 \pm 7.6$ ) $\mu \mathrm{m}$ long (excluding conidial mass) consisting of 2-4 series of branches-type B (more than two branches) (Jacobs and Wingfield 2001) (Fig. 9g). Primary branches dark olivaceous, cylindrical, smooth, 11.5-19.5 $\times$ 2.8-5.5 $\mu \mathrm{m}$. Conidiogenous cells hyaline, tapering from base to apex, 14.1-25.7 (mean $18.4 \pm 2.4$ ) $\times$ 1.9-2.6 (mean $2.1 \pm 0.15) \mu \mathrm{m}$. Conidia (Fig. 9h) hyaline, ellipsoidal to cylindrical, 3.9-8.1 (mean $5.6 \pm 0.91) \times 1.2-2.9$ (mean $1.9 \pm 0.36) \mu \mathrm{m}$, accumulating around the conidiogenous apparatus as a light yellow mucilaginous mass.

Cultural characteristics Colonies on MEA hyaline at first, becoming light rusty and later darker, mycelium appressed and immersed (Fig. 9i). Colony margin effuse. Hyphae amber yellow in colour (Kornerup and Wanscher 1978), smooth, slightly constricted at the septa, 1.7-6.1 (mean 3.4 \pm 0.9 ) $\mu \mathrm{m}$ diam. Perithecia and Leptographium asexual morph co-occur in culture. Optimal growth temperature is $25{ }^{\circ} \mathrm{C}$, radial growth rate $1.5( \pm 0.1) \mathrm{mm} / \mathrm{d}$, growth reduced at 10 and $15{ }^{\circ} \mathrm{C}$, no growth at 5 and $35{ }^{\circ} \mathrm{C}$.

Host trees Alnus incana, Fagus sylvatica, Fraxinus exselsior, Quercus robur

Insect Trypodendron domesticum, $T$. vector signatum, Dryocoetes alni

Distribution Norway, Poland

Type material POLAND, Rozpucie, from Trypodendron domesticum beetle infesting Fagus sylvatica, 29 August 2015, R. Jankowiak, holotype TUR http:// mus.utu.fi/TFU.207251, culture ex-holotype CBS 

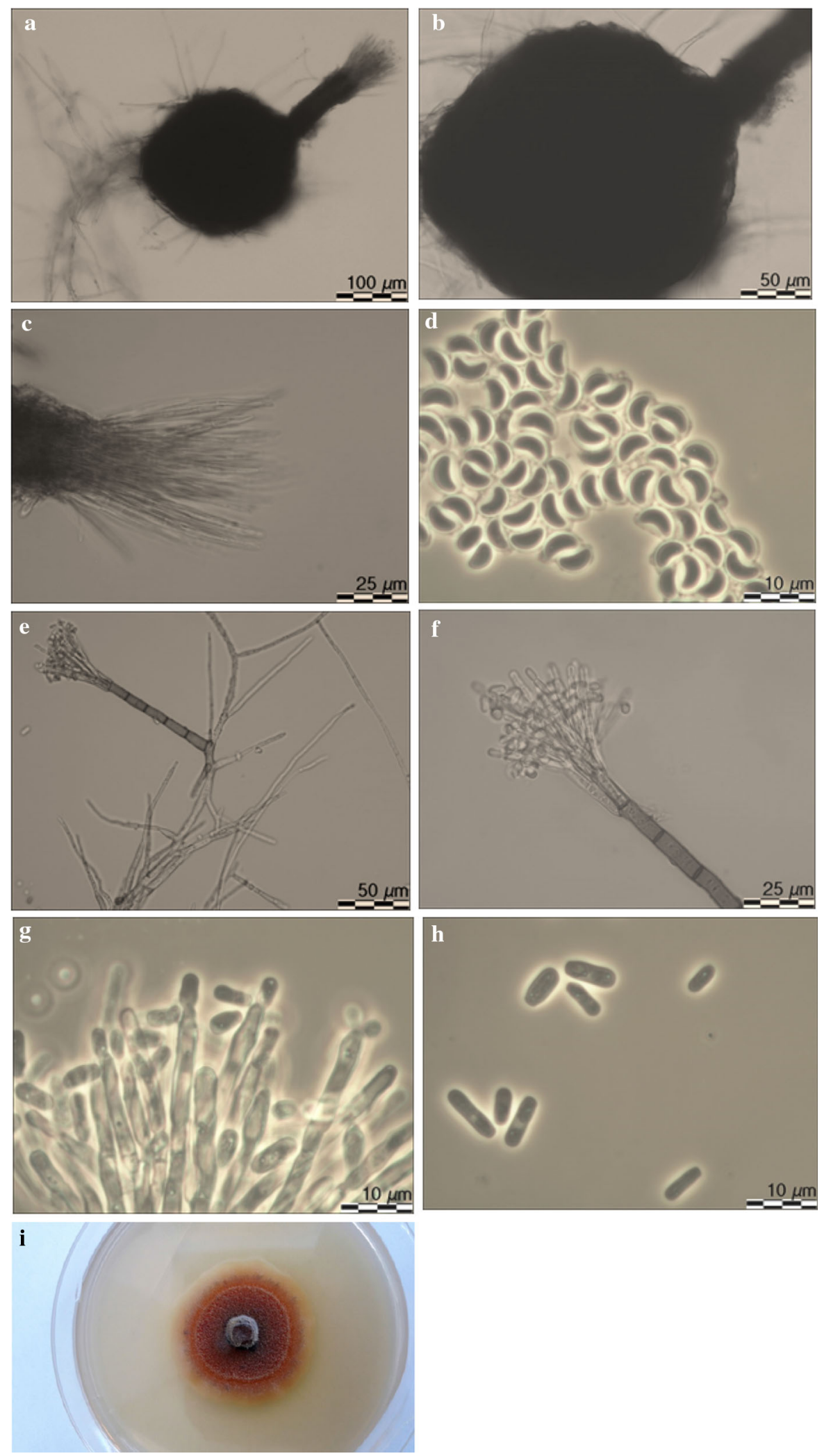
4 Fig. 9 Morphological characteristics of Leptographium tardum sp. nov. (CBS 144091). a ascoma, b ascomatal base, $\mathbf{c}$ ostiolar hyphae, $\mathbf{d}$ ascospores, $\mathbf{e}$ and $\mathbf{f}$ conidiophore, $\mathbf{g}$ conidiogenous apparatus, $\mathbf{h}$ conidia, $\mathbf{i}$ fourteen day old culture on MEA

144091 = CMW 51789; POLAND, Zabierzów, from Trypodendron domesticum beetle infesting Fagus sylvatica, 24 January 2014, R. Jankowiak, paratype TUR http://mus.utu.fi/TFU.207252, culture ex-paratype CBS $144092=\mathrm{CMW}$ 51790; NORWAY, Troms, from Trypodendron signatum beetle infesting Alnus incana, 27 September 2016, G. Kvammen, paratype TUR http://mus.utu.fi/TFU.207249, culture ex-paratype CBS 144087 = CMW 51784.

Notes Isolates of L. tardum grouped close to $O$. brevicolle in the phylogenetic analyses of the LSU and ITS sequences (Figs. 3, 4), however they can clearly be separated from this fungus based on sequences of the four protein-coding genes (Figs. 5, 6, 7, 8).

Morphologically, L. tardum differs from $O$. brevicolle in having larger ascospores and conidia, and the presence of ostiolar hypha on the ascomatal neck. In addition, $L$. tardum produces rusty-yellowish cultures in contrast to the olivaceous colored colonies of $O$. brevicolle. The optimal growth on MEA for $L$. tardum is $25^{\circ} \mathrm{C}$ while for $O$. brevicolle optimal growth is at $30{ }^{\circ} \mathrm{C}$. Morphologically, L. tardum is more similar to G. francke-grosmanniae. However, L. tardum produces larger ascospores and conidia, condiophores are without rhizoids, and colonies are not olivaceous.

Leptographium tardum was isolated from various beetle species on $A$. incana in two sample plots in south-eastern Norway and one area in northern Norway. At these sites among the following beetles sampled L. tardum was recovered from T. signatum, $T$. domesticum, and D. alni 95,7 , and 3\% respectively. Leptographium tardum was also recorded on $T$. domesticum recovered from $F$. excelsior and $Q$. robur on the same sample plots. In contrast to Norway, L. tardum was rarely found in association with $T$. domesticum from $F$. sylvatica in Poland. It was isolated from $1 \%$ of the beetles collected from $F$. sylvatica logs.
Taxon 2

Leptographium vulnerum R. Jankowiak and A. Ostafińska, sp. nov. (Fig. 10). MycoBank: 826760.

Etymology Name refers to wound of tree where the holotype and other specimens were collected.

Sexual state develops on malt agar in 21 days. Perithecia superficial on wood and agar, bases black, globose, unornamented, 123.4-226,1 (mean $177.4 \pm 28.6) \mu \mathrm{m}$ in diameter, necks dark brown, cylindrical, straight, 341-617.7 (mean $455.3 \pm 85.1) \mu \mathrm{m}$ long (including ostiolar hyphae), 39-77 (mean $48.7 \pm 9.5$ ) $\mu \mathrm{m}$ wide at base, 24.7-42.6 (mean $35.3 \pm 4.8) \mu \mathrm{m}$ wide at the tip (Fig. 10a, b). Ostiolar hyphae present, pale brown, straight, septate, numerous, divergent, tapering at the tip, up to $116 \mu \mathrm{m}$ long (Fig. 10c). Asci not seen. Ascospores one-celled, hyaline, orange section shaped in side view, ellipsoidal in the face view, globose in end view, 4.2-6.1 (mean $5.1 \pm 0.38) \times 1.9-3.5$ (mean $2.5 \pm 0.4) \mu \mathrm{m}$ including hyaline gelatinous sheath, $0.2-0.7 \mu \mathrm{m}$ thick (Fig. 10d).

Asexual states: (1): Conidiophores (type 1): macronematous, arising directly from hyphae, without rhizoidal hyphae at the bases but often secondary conidiophores emerge from the base of primary conidiophores, $119-170$ (mean $142.4 \pm 12.3$ ) $\mu \mathrm{m}$ in length (Figs. 10e-g). Stipes erect, olivaceous, 3-14 septate, $79-117$ (mean $95.2 \pm 12.3$ ) $\mu \mathrm{m}$ long from first basal septum to below primary branches, 5.3-8.7 (mean $6.6 \pm 0.7) \mu \mathrm{m}$ wide below primary branches, apical cell not swollen, 6.3-9.5 (mean $7.9 \pm 0.7) \mu \mathrm{m}$ wide at base, basal cell not swollen. Conidiogenous apparatus 39.4-71.1 (mean $48.8 \pm 6.6) \mu \mathrm{m}$ long (excluding conidial mass) consisting of (1-) 2 (-3) series of branches-type B (more than two branches) (Jacobs and Wingfield 2001) (Fig. 10h). Primary branches dark olivaceous, cylindrical, smooth, 10.3-17.2 × 2.6-5.7 $\mu \mathrm{m}$. Conidiogenous cells hyaline, tapering from base to apex, 11.9-24 (mean $16.6 \pm 2.4) \times 1.6-2.7($ mean $2.2 \pm 0.3) \mu \mathrm{m}$. Conidia hyaline, oblong to elliptical, sometimes obovate (Fig. 10h), 2.7-5.1 (mean $3.9 \pm 0.47) \times 0.8-1.9$ (mean $1.5 \pm 0.2) \mu \mathrm{m}$, accumulating around the conidiogenous apparatus in a creamy mucilaginous mass.

(2): Conidiophores (type 2): occurring singly or in groups, mostly on aerial mycelia or emerge from the base of conidiophores as described above, macronematous, mononematous, 24.4-41.8 (mean $31.6 \pm 4.7$ ) 
$\mu \mathrm{m}$ in length including the conidial mass, rhizoid like structures absent (Figs. 8e, i). Stipes hyaline or light olivaceous, simple, 1-4 septate, 13.2-26.7 (mean
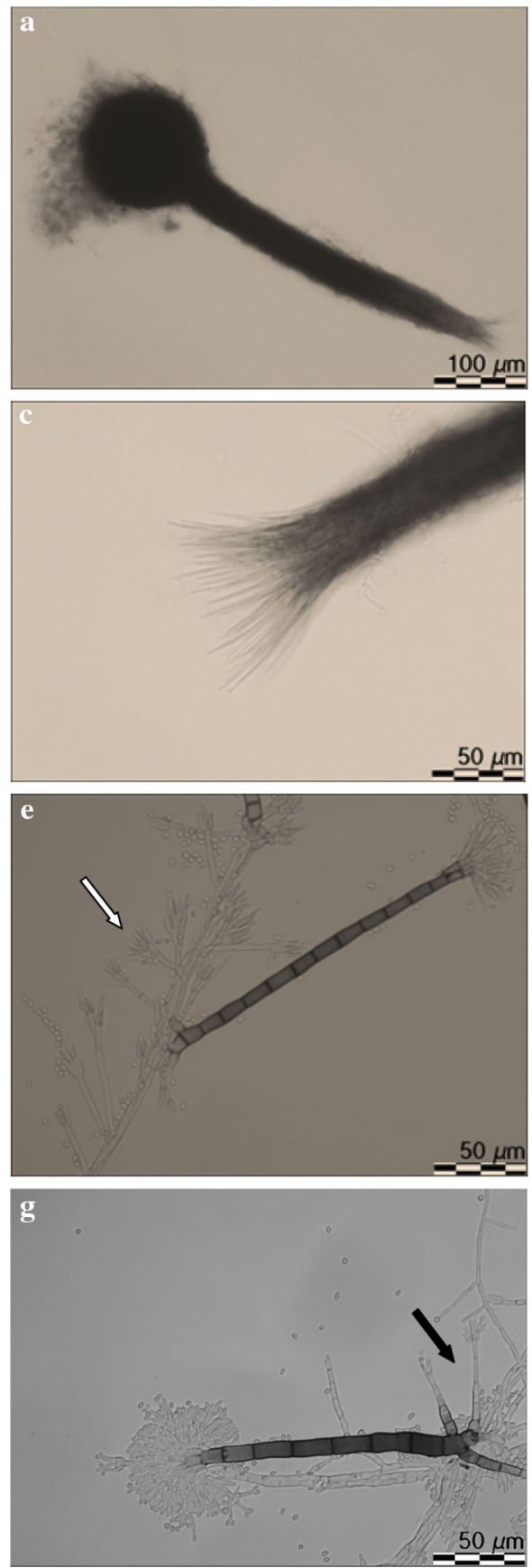

Fig. 10 Morphological characteristics of Leptographium vulnerum sp. nov. (CBS 144096). a ascoma, b ascomatal base, c ostiolar hyphae, $\mathbf{d}$ ascospores, $\mathbf{e}-\mathbf{g}$ conidiophores (type 1), white arrow indicates conidiophores of type 2, black arrow indicates secondary conidiophores emerging from base of
$18.3 \pm 3.0) \mu \mathrm{m}$ long, 1.3-2.9 (mean $2 \pm 0.3$ ) $\mu \mathrm{m}$ wide below primary branches. Conidiogenous apparatus with 1-2 series of cylindrical branches (Fig. 10j).
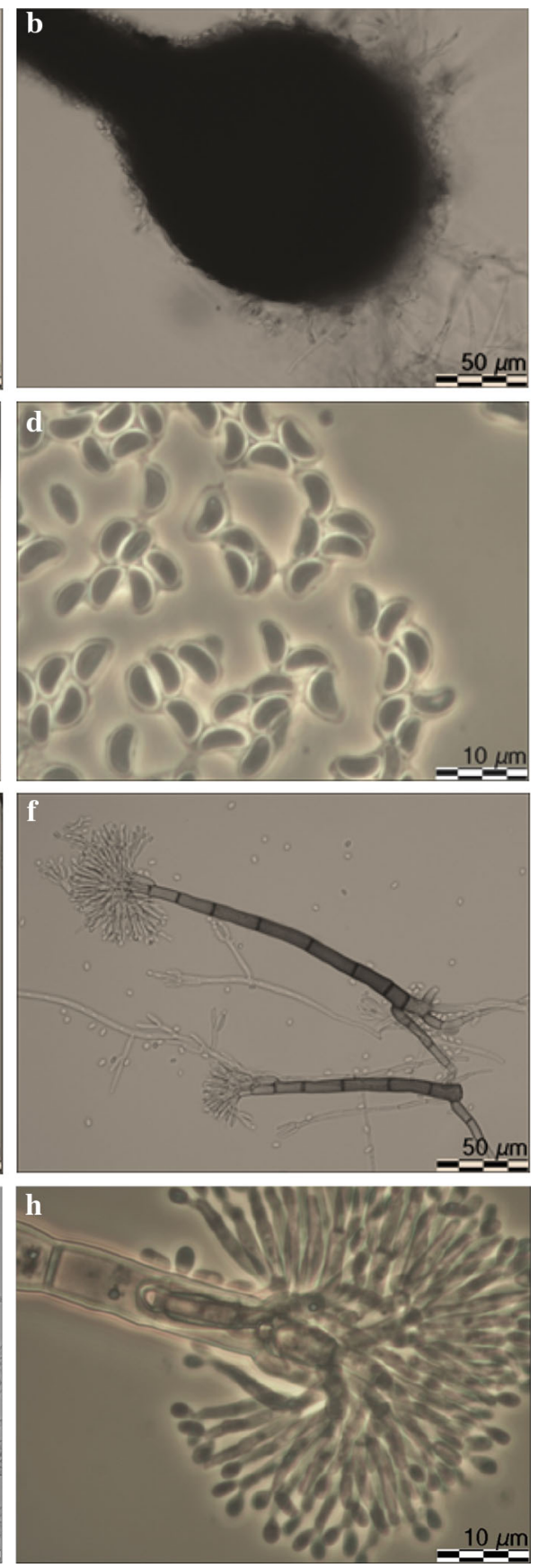

primary conidiophores, $\mathbf{h}$ conidiogenous apparatus of conidiophores type 1, i conidiophores (type 2), $\mathbf{j}$ conidiogenous apparatus of conidiophore type $2, \mathbf{k}$ conidia, $\mathbf{l}$ fourteen day old culture on MEA 

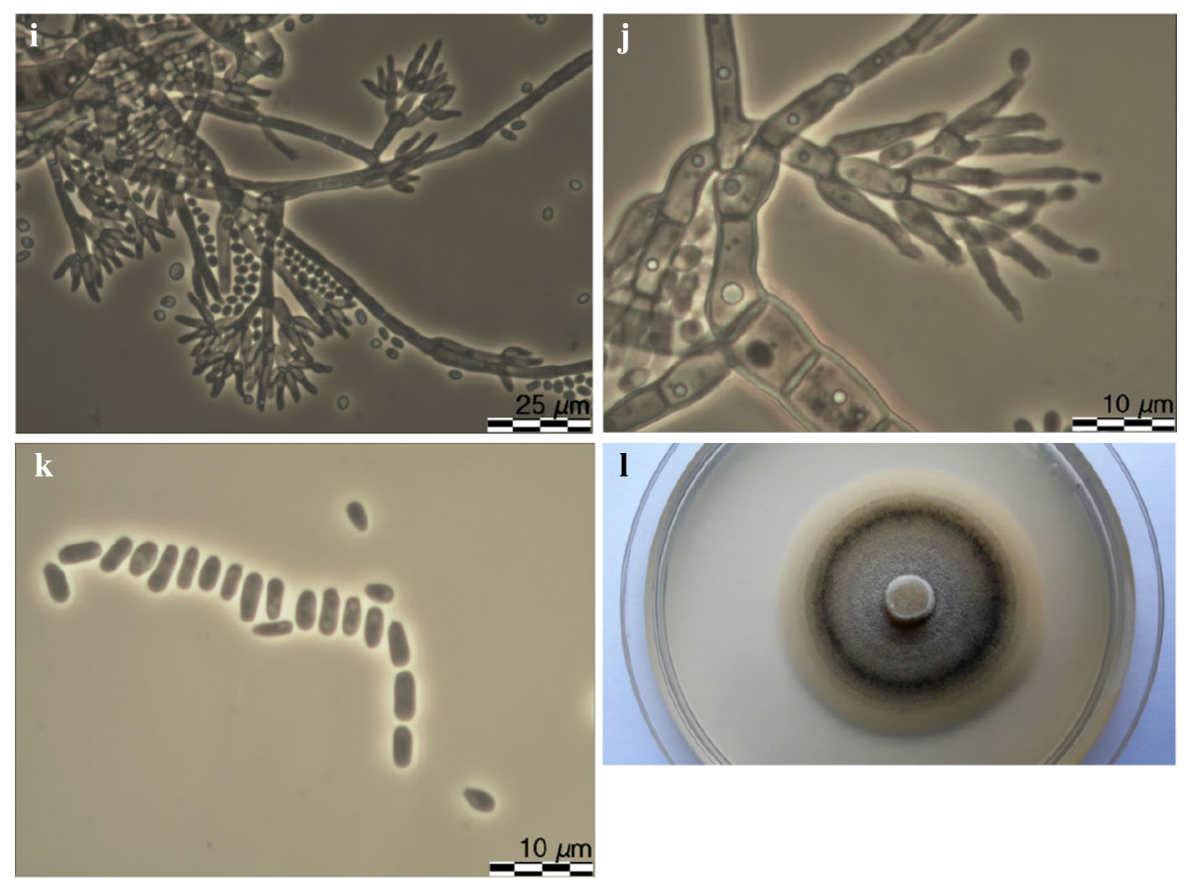

Fig. 10 continued

Primary branches, 2-4, light olivaceous, smooth, cylindrical aseptate, 5.7-20.3 (mean $11.3 \pm 3.2$ ) $\mu \mathrm{m}$ long, 1.2-2.8 (mean $2 \pm 0.4$ ) $\mu \mathrm{m}$ wide arrangement of the primary branches on the stipe-type B (more than two branches) (Jacobs and Wingfield 2001). Conidiogenous cells discrete, 2-4 per branch, cylindrical, tapering slightly at the apex, 4.5-12.8 (mean $7.9 \pm 1.7) \mu \mathrm{m}$ long and 0.7-2.6 (mean $1.5 \pm 0.4) \mu \mathrm{m}$ wide. Conidia hyaline, oblong to elliptical, sometimes obovate, 1.4-2.8 (mean $2 \pm 0.35) \times 0.8-2.2($ mean $1.5 \pm 0.26) \mu \mathrm{m}$.

Cultural characteristics: Colonies on MEA hyaline at first, later becoming light greyish in the centre, with a darker edge; mycelium appressed and immersed (Fig. 101). Colony margin smooth. Hyphae hyaline or pale grey in colour (Kornerup and Wanscher 1978), smooth, submerged in the medium and aerial mycelium sparse, not constricted at the septa, 0.9-3.4 (mean $1.9 \pm 0.6) \mu \mathrm{m}$ diam.

Perithecia and asexual morphs co-occur in culture. Optimal growth temperature is $20^{\circ} \mathrm{C}$, radial growth rate $2.4( \pm 0.1) \mathrm{mm} / \mathrm{d}$, growth reduced at $25^{\circ} \mathrm{C}$, no growth at 5,30 and $35^{\circ} \mathrm{C}$.

Host trees Carpinus betulus, Fagus sylvatica, Quercus robur, Quercus rubra
Insect unknown

vector

Substrate natural fresh lesions (necrosis) on tree stem

Distribution Poland

Type material POLAND, Babimost, from Fagus sylvatica wood, 26 May 2016, R. Jankowiak, holotype TUR http://mus.utu.fi/TFU.207255, culture ex-holotype CBS 144096 = CMW 51794; POLAND, Babimost, from Carpinus betulus wood, 26 May 2016, $R$. Jankowiak, paratype TUR http://mus.utu.fi/TFU. 207254, culture ex-paratype CBS $144094=\mathrm{CMW}$ 51792; POLAND, Wierzchosławice, from Quercus rubra wood, 13 October 2016, R. Jankowiak, paratype TUR http://mus.utu.fi/TFU.207256, culture ex-paratype CBS $144097=$ CMW 51795.

Notes Isolates of $L$. vulnerum grouped close to $L$. flavum in the phylogenetic analyses of the ITS and LSU sequences (Figs. 3, 4), but can be clearly separated based on sequences of the four proteincoding genes (Figs. 5-8). These two species differ in $4 \mathrm{bp}$ nucleotide positions with regards to $\beta$-tubulin (Table S1) and by 31 bp with regards to the TEF- $1 \alpha$ sequence (Table S2). The phylogenetic analysis of the ITS and BT sequences showed that $L$. vulnerum and $L$. 
flavum are closely related to $G$. francke-grosmanniae (Figs. 4, 5).

Morphologically, L. vulnerum differs from $G$. francke-grosmanniae in having larger perithecial bases and necks, larger ascospores and the presence of conidiophores without rhizoids. Leptographium vulnerum produces two types of conidiophores: large darkly pigmented conidiophores and non-pigmented conidiophores with short stipes. In addition, $L$. vulnerum generates greyish cultures and the optimal growth on MEA is at $20{ }^{\circ} \mathrm{C}$.

Morphologically, $L$. vulnerum is most similar to $L$. flavum. Both species produce two types of conidiophores. The greatest differences between these species with regarding to morphology are that $L$. vulnerum produces larger perithecial bases and necks, and larger ascospores. Furthermore, L. vulnerum grows slowly at temperatures that exceed $20^{\circ} \mathrm{C}$, while growth of $L$. flavum is only slightly reduced at $25{ }^{\circ} \mathrm{C}$. In contrast to L. flavum, no growth of L. vulnerum is observed at $30{ }^{\circ} \mathrm{C}$. Leptographium vulnerum produces greyish cultures, while L. falvum forms deep yellowish cultures with clear rings.

Leptographium vulnerum was isolated from lesions on the following hardwoods respectively in $8,6,4$, and $0.7 \%$ in six sample plots in southern Poland: Q. rubra, $C$. betulus, $Q$. robur, and F. sylvatica.

\section{Taxon 3}

Leptographium flavum R. Jankowiak and A. Ostafińska, sp. nov. (Fig. 11). MycoBank: 826761.

Etymology Name refers to yellow pigment produced by this fungus on malt agar.

Sexual state develops on malt agar in 21 days. Perithecia superficial on wood and agar, bases light brown to dark brown, globose, unornamented, 94.6-203.9 (mean $138.6 \pm 29.1$ ) $\mu \mathrm{m}$ in diameter, necks dark brown, cylindrical, straight, 285.2-377.2 (mean $336.6 \pm 35) \mu \mathrm{m}$ long (including ostiolar hyphae), 33-63.7 (mean $45.1 \pm 8.4) \mu \mathrm{m}$ wide at base, 18.9-35.9 (mean $27.2 \pm 3$ ) $\mu \mathrm{m}$ wide at the tip (Figs. 11a, b). Ostiolar hyphae present, pale brown, straight, septate, numerous, divergent, tapering at the tip, up to $84.6 \mu \mathrm{m}$ long (Fig. 11c). Asci not seen. Ascospores one-celled, hyaline, orange section shaped in side view, ellipsoidal in face view, globose in end view, 4.4-6.4 (mean 5.4 \pm 0.46 ) $\times$ 2.5-3.9 (mean
$3.2 \pm 0.37) \mu \mathrm{m}$ including hyaline gelatinous sheath, $0.3-1.2 \mu \mathrm{m}$ thick (Fig. 11d).

Asexual states: (1) Conidiophores (type 1): macronematous, arising directly from hyphae, without rhizoidal hyphae at the bases but often secondary conidiophores emerge from the base of the primary conidiophores, 111.6-189.1 (mean $143 \pm 15.4) \mu \mathrm{m}$ in length (Fig. 11e-g). Stipes erect, olivaceous, 3-8 septate, 69.3-124 (mean $91.2 \pm 12.46$ ) $\mu \mathrm{m}$ long from first basal septum to below primary branches, 4.1-8.4 (mean $6.1 \pm 1) \mu \mathrm{m}$ wide below primary branches, apical cell not swollen, and 6.8-10.4 (mean $8.5 \pm 0.96) \mu \mathrm{m}$ wide at base, basal cell not swollen. Conidiogenous apparatus 34.1-66.4 (mean $50.6 \pm 7.5) \mu \mathrm{m}$ long (excluding conidial mass) consisting of (1-) 2 (-3) series of branches-type B (more than two branches) (Jacobs and Wingfield 2001) (Fig. 11h). Primary branches dark olivaceous, cylindrical, smooth, 9.2-19.1 × 2.2-7.4 $\mu \mathrm{m}$. Conidiogenous cells hyaline, tapering from base to apex, 17.7-43.1 (mean $28.3 \pm 6.2$ ) × 1.6-2.7 (mean $2.1 \pm 0.27) \mu \mathrm{m}$. Conidia (Fig. 11j) hyaline, oblong to elliptical, sometimes obovate, 3.5-6 (mean $4.6 \pm 0.62) \times 1.2-3.3$ (mean $1.9 \pm 0.32) \mu \mathrm{m}$, accumulating around the conidiogenous apparatus in a hyaline mucilaginous mass.

(2): Conidiophores (type 2): occurring single or in groups, mostly on aerial mycelia but often emerge from the base of conidiophores as described above, macronematous, mononematous, 22.7-39.7 (mean $31.2 \pm 4.2) \mu \mathrm{m}$ in length including the conidial mass, rhizoid like structures absent (Figs. 11f, g, i). Stipes olivaceous, simple, 0-5 septate, 10.9-25.3 (mean $16.9 \pm 2.7) \mu \mathrm{m}$ long, 1.5-2.6 (mean $2 \pm 0.3) \mu \mathrm{m}$ wide below primary branches. Conidiogenous apparatus with 1-2 series of cylindrical branches. Primary branches, 2-4, light olivaceous, smooth, cylindrical aseptate, 6.8-26.7 (mean $11.5 \pm 4.2$ ) $\mu \mathrm{m}$ in length and 1.2-2.2 $\mu \mathrm{m}$ (mean $1.7 \pm 0.3$ ) wide, arrangement of the primary branches on the stipe-type B (more than two branches; Jacobs and Wingfield 2001). Conidiogenous cells discrete, 2-4 per branch, cylindrical, taper slightly at the apex, 6.7-13.7 (mean $9.3 \pm 3.7) \mu \mathrm{m}$ long and 1.0-2.3 (mean $1.5 \pm 0.3) \mu \mathrm{m}$ wide. Conidia hyaline, oblong to elliptical, $1.0-2.8$ (mean $1.8 \pm 0.44) \times 0.7-2.0$ (mean $1.2 \pm 0.3) \mu \mathrm{m}$.

Cultural characteristics Colonies on MEA hyaline at first, later becoming vividly yellowish in the centre, 
concentric rings present, mycelium appressed and immersed (Fig. 11k). Yellow pigment was often produced on MEA. Colony margin smooth. Hyphae
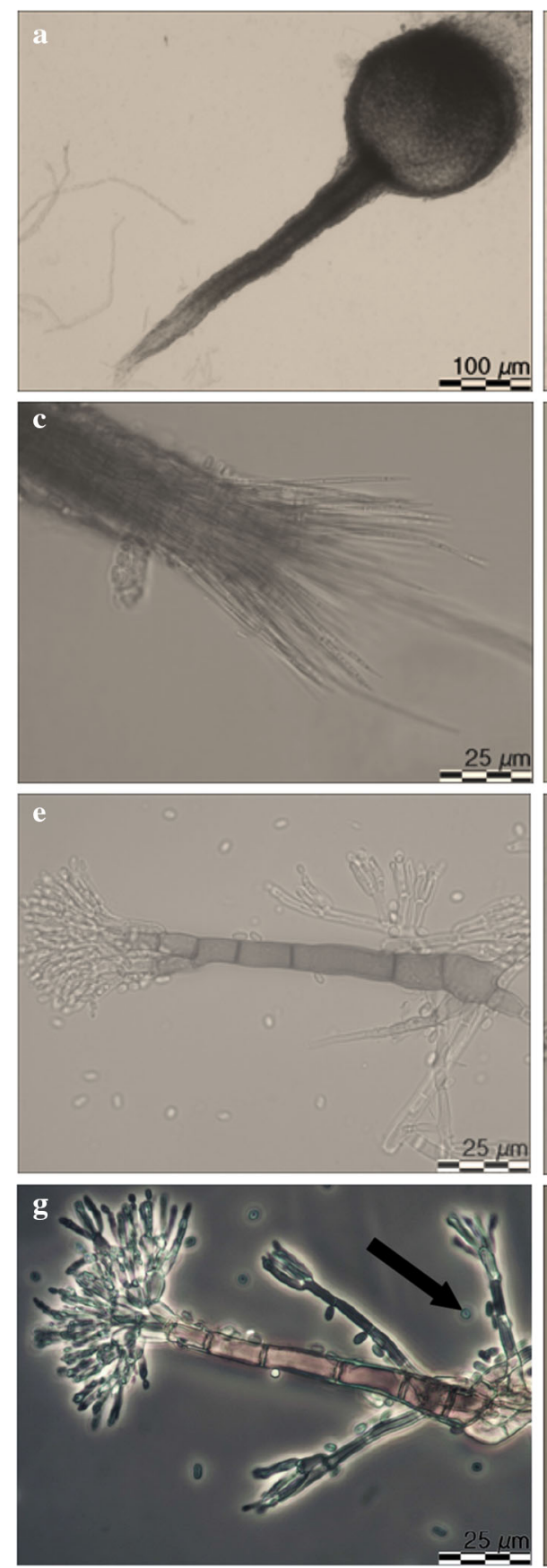

Fig. 11 Morphological characteristics of Leptographium flavum sp. nov. (CBS 144099). a ascoma, b ascomatal base, c ostiolar hyphae, d ascospores, e-g conidiophores (type 1), black arrow indicates conidiophores of type 2, white arrow indicates secondary conidiophores emerging from base of pale or light yellow in colour (Kornerup and Wanscher 1978), smooth, submerged in the medium and aerial mycelium abundant, not constricted at the septa, 0,9-4
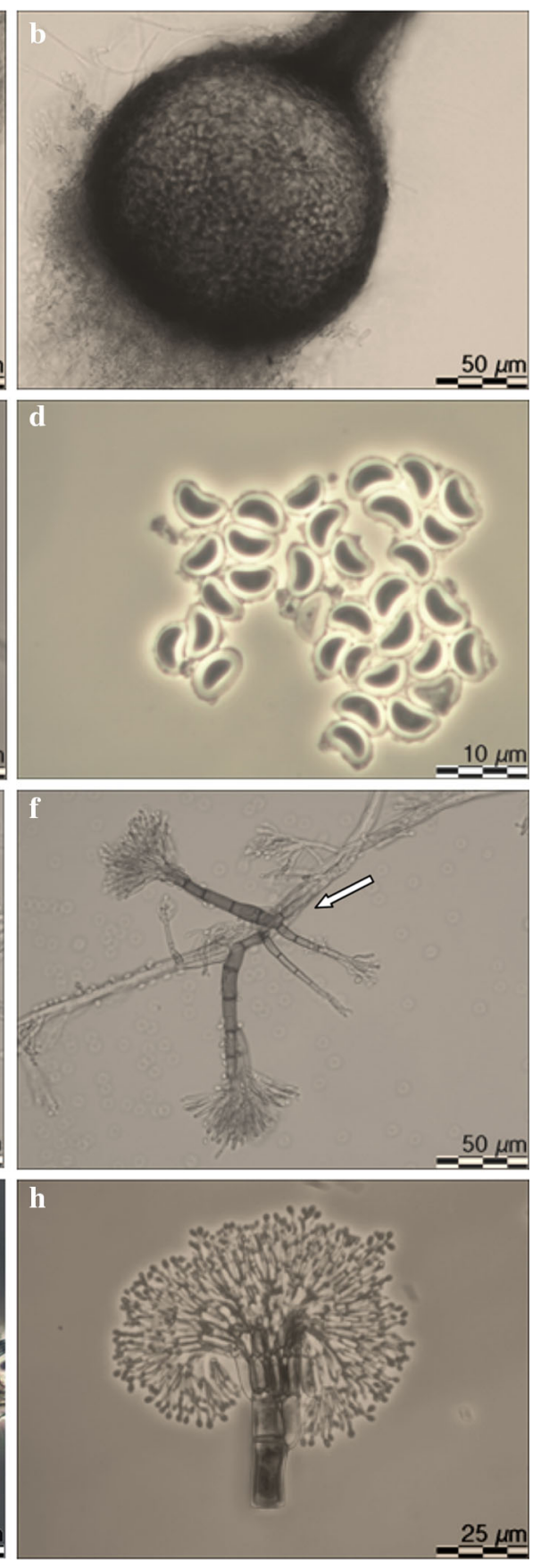

primary conidiophores conidiophores (type 1), white arrow indicated secondary conidiophores emerging from base of primary conidiophores, $\mathbf{h}$ conidiogenous apparatus (conidiophores of type 1), i conidiophores (type 2), $\mathbf{j}$ conidia, $\mathbf{k}$ fourteen day old culture on MEA 

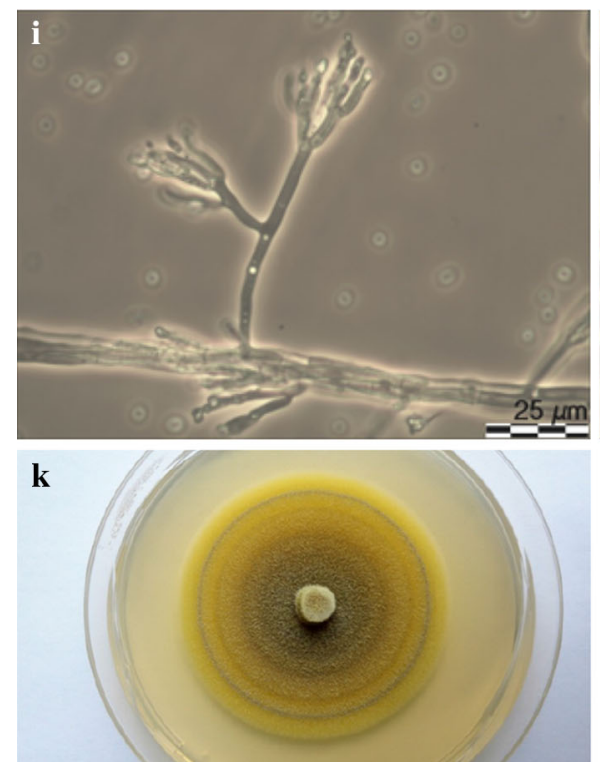

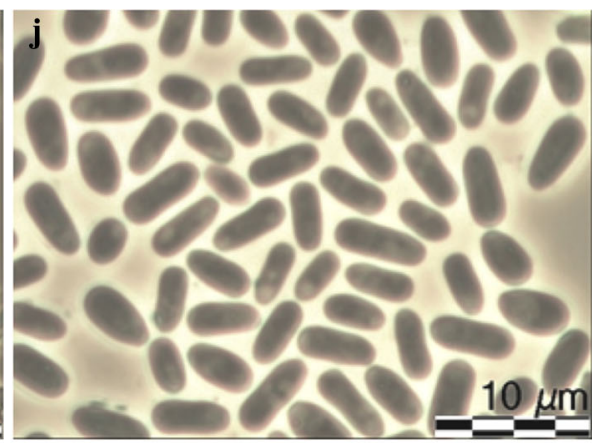

Fig. 11 continued

(mean $2.2 \pm 0.7) \mu \mathrm{m}$ diam. Perithecia and asexual morphs co-occur in culture. Optimal growth temperature is $20{ }^{\circ} \mathrm{C}$, radial growth rate $3.0( \pm 0.1) \mathrm{mm} / \mathrm{d}$, growth slightly reduced at 25 and $30{ }^{\circ} \mathrm{C}$, no growth at $35{ }^{\circ} \mathrm{C}$.

$\begin{array}{ll}\begin{array}{ll}\text { Host trees } \\ \text { Substrate }\end{array} & \begin{array}{l}\text { Quercus robur, Quercus rubra } \\ \text { natural fresh lesions (necrosis) on tree } \\ \text { stem }\end{array} \\ \begin{array}{l}\text { Insect } \\ \text { vector }\end{array} & \text { Anisandrus dispar } \\ \text { Distribution } & \text { Poland }\end{array}$

Type material POLAND, Wierzchosłwice, from Quercus robur wood, 7 October 2015, R. Jankowiak, holotype TUR http://mus.utu.fi/TFU.207257, culture ex-holotype CBS 144099 = CMW 51797; POLAND, Wierzchosłwice, from Quercus robur wood, 7 October 2015, R. Jankowiak, paratype TUR http://mus.utu.fi/ TFU.207260, culture ex-paratype CBS $144102=$ CMW 51800; POLAND, Resko, from Aisandrus dispar beetle infesting Quercus robur, 7 October 2016, $R$. Jankowiak, paratype TUR http://mus.utu.fi/TFU. 207261, culture ex-paratype CBS $144105=\mathrm{CMW}$ 51804.

Notes The morphologically differences between $L$. flavum and L. vulnerum have been described above in section: Notes on L. vulnerum.
Leptographium flavum was found in 25 and $17 \%$ of $Q$. rubra and $Q$. robur lesions from trees, respectively, in six sample plots in southern Poland. It was also recorded on $2 \%$ of $A$. dispar beetles in one study plot in Poland.

\section{Discussion}

Three new species of Leptographium were discovered from European hardwoods in this study. These new taxa are closely related to the species of the $G$. olivacea complex, but formed two separate, wellsupported lineages. The first lineage consists of $L$. tardum sp. nov. and O. brevicolle, while in the second lineage resides $L$. vulnerum sp. nov. and L. flavum sp. nov. G. francke-grosmanniae has also affiliation to $L$. vulnerum and L. flavum based on analysis of the ITS and B-tubulin sequences. The sexual states of these three new species were highly similar to those from species that comprise the G. olivacea complex (globose ascomata with cylindrical necks terminated by ostiolar hyphae at their apices, and orange-section shaped ascospores with cucullate gelatinous sheaths). However, in contrast to the species of the G. olivacea complex that produce synnematous asexual states, all three new species produce mononematous morphs. The three new species are characterized by dark 
pigmented mononematous conidiophores that resembling those produced by $G$. francke-grosmanniae, but with the difference that they did not form rhizoids. In addition, L. vulnerum and L. flavum produce a second type of mononematous conidiophores. These conidiophores have short, non-pigmented stipes developing directly from vegetative hyphae. Another important feature in distinguish these species is that these secondary conidiophores often develop from cells at the base of the primary conidiophores thus generating both type of conidiophores. These species can also be distinguished by their ecological niches; L. tardum has been found only in association with hardwoodsinfesting insects while L. vulnerum and L. flavum were mainly associated with tree wounds.

The phylogenetic analysis and differences in asexual morphology of the three new species suggest that these species, together with $O$. brevicolle and $G$. francke-grosmanniae form two well-supported genetic lineages in Leptographium s.l. consisting only of hardwood-infecting species. Ophiostoma brevicolle was collected from Populus tremuloides Michx. in the USA (Davidson 1958), while G. francke-grosmanniae was isolated from the large timberworm beetle, Hylecoetus dermestoides (L.) (Coleoptera: Lymexylidae), infesting a Quercus sp. (Davidson 1971). In turn, L. tardum is a potential symbiotic associate of the European hardwood ambrosia beetle, T. domesticum, and the $T$. signatum. These ambrosia beetles attack different hardwood tree species in Europe and are known to prefer fallen or weakened trees and stumps (Wood and Bright 1992). Leptographium tardum has been isolated from Trypodendron spp. with variably frequencies, suggesting that the role of this fungus in the life-cycle of the ambrosia beetles is not important. The other newly described Leptographium species, $L$. vulnerum and L. flavum colonized fresh lesions on tree stems. Wounds and cracks that may be caused by animals, wind, frost, silvicultural practices and various arthropods (Heath et al. 2010), are essential entry points for ophiostomatoid fungi (Wingfield and Kemp 1993). However, despite the importance of ophiostomatoid fungi as possible serious tree pathogens, very little is known regarding the biodiversity of ophiostomatoid fungi associated with wounds on trees. Studies from South Africa, Australia and South America provide evidence that wounds on hardwood trees provide habitat for a large diversity of ophiostomatoid fungi (Barnes et al. 2003; Geldenhuis et al.
2004; Roux et al. 2004; Grobbelaar et al. 2010; Kamgan Nkuekam et al. 2008, 2011a, b, 2012; Osorio et al. 2016). Relatively little is known about ophiostomatoid species infecting wounds on hardwood trees in Europe. Recently, Kamgan Nkuekam et al. (2010) recorded Ophiostoma quercus (Georgev.) Nannf., O. borealis, G. Kamgan Nkuekam, H. Solheim and Z.W. de Beer and $O$. denticiliatum Linnak., Z.W. de Beer and M.J. Wingf. from wounds of native broad-leaved trees in Norway. Our studies have confirmed the ability of Leptographium spp. to infect hardwood trees in Europe although pathogenicity tests are needed to determine their pathogenicity towards hardwoods. In general, natural infections might be the result of wind or rain splash dispersal of propagules, or by transmission of inoculum by arthropod vectors (Malloch and Blackwell 1993; Six 2003; Klepzig and Six 2004; Hayslett et al. 2008; Juzwik et al. 2008). The association of L. flavum with A. dispar, as noted in this study, suggests that some beetle species, for example sap or ambrosia beetles that infest tree lesions can spread fungal spores in forest environments.

In comparison with conifer-infesting Leptographium spp., the taxonomy, diversity and pathogenicity of hardwood-infesting Leptographium species have been poorly studied. The results of this study have shown that Leptographium spp. are not rare inhabitants of hardwood forests in Europe, and suggest that these fungi may commonly infect wounds on hardwoods trees. Therefore, it will be important to expand these surveys to cover larger geographic areas including more habitats in Europe.

Acknowledgements This work was supported by the National Science Centre, Poland (Contract No. UMO-2014/15/NZ9/ 00560). The work in Norway is partly financed by the Norwegian biodiversity information centre and includes beetles collected in northern Norway as a part of a Master thesis T.A. Leif Evje and Geir Kvammen. Torstein Kvamme checked the identity of beetles.

\section{Compliance with ethical standards}

Conflict of interest The authors declare that they have no conflict of interest.

Ethical approval All applicable international, national, and/ or institutional guidelines for the care and use of animals were followed.

Open Access This article is distributed under the terms of the Creative Commons Attribution 4.0 International License (http:// 
creativecommons.org/licenses/by/4.0/), which permits unrestricted use, distribution, and reproduction in any medium, provided you give appropriate credit to the original author(s) and the source, provide a link to the Creative Commons license, and indicate if changes were made.

\section{References}

Barnes I, Roux J, Wingfield BD, Dudzinski MJ, Old KM, Wingfield MJ (2003) Ceratocystis pirilliformis, a new species from Eucalyptus nitens in Australia. Mycologia 95:865-871

Darriba D, Taboada GL, Doallo R, Posada D (2012) jModelTest 2: more models, new heuristics and parallel computing. Nat Methods 9(8):772. https://doi.org/10.1038/nmeth.2109

Davidson RW (1958) Additional species of Ophiostomataceae from Colorado. Mycologia 50:661-670

Davidson RW (1971) New Species of Ceratocystis. Mycologia 63:5-15

De Beer ZW, Wingfield MJ (2013) Emerging lineages in the Ophiostomatales. In: Seifert KA, De Beer ZW, Wingfield MJ (eds) The Ophiostomatoid fungi: expanding frontiers, CBS Biodiversity Series 12. CBS Press, Utrecht, pp 21-46

Duong TA, De Beer ZW, Wingfield BD, Wingfield MJ (2012) Phylogeny and taxonomy of species in the Grosmannia serpens complex. Mycologia 104:715-732

Gardes M, Bruns TD (1993) ITS primers with enhanced specificity for Basidiomycetes - application to the identification of mycorrhiza and rusts. Mol Ecol 2:113-118

Geldenhuis MM, Roux J, Montenegro F, De Beer ZW, Wingfield MJ, Wingfield BD (2004) Identification and pathogenicity of Graphium and Pesotum species from machete wounds on Schizolobium parahybum in Ecuador. Fungal Divers 15:137-151

Glass NL, Donaldson GC (1995) Development of primer sets designed for use with the PCR to amplify conserved genes from filamentous ascomycetes. App Environ Microbiol 61:1323-1330

Goheen DJ, Cobb FW (1978) Occurrence of Verticicladiella wageneri and its perfect state, Ceratocystis wageneri sp. nov., in insect galleries. Phytopathology 68:1192-1195

Goidànich G (1936) II genre di Ascorniceti 'Grosmanni' G. Goid. Bolletino della Stazione di Patologia vegetale di Roma 16:26-40

Grobbelaar J, de Beer ZW, Bloomer P, Wingfield MJ, Wingfield BD (2010) Ophiostoma tsotsi sp. nov., a wound- infesting fungus of hardwood trees in Africa. Mycopathologia 169:413-423. https://doi.org/10.1007/s11046-009-9267-8

Guindon S, Gascuel O (2003) A simple, fast and accurate method to estimate large phylogenies by maximum-likelihood. Syst Biol 52:696-704. https://doi.org/10.1080/ 10635150390235520

Guindon S, Dufayard JF, Lefort V, Anisimova M, Hordijk W, Gascuel O (2010) New algorithms and methods to estimate maximum-likelihood phylogenies: assessing the performance of PhyML 3.0. Syst Biol 59:307-321. https://doi. org/10.1093/sysbio/syq010
Hawksworth DL (2011) A new dawn for the naming of fungi: impacts of decisions made in Melbourne in July 2011 on the future publication and regulation of fungal names. IMA Fungus 2:155-162

Hayslett M, Juzwik J, Moltzan B (2008) Three colopterus beetle species carry the oak wilt fungus to fresh wounds on red oak in Missouri. Plant Dis 92:270-275

Heath RN, Linde M, Van Groeneveld H, Wingfield BD (2010) Factors influencing infection of Acacia mearnsii by the wilt pathogen Ceratocystis albifundus in South Africa. For Pathol 40(6):500-509

Jacobs K, Wingfield MJ (2001) Leptographium species: tree pathogens, insect associates, and agents of blue-stain. The American Phytopathological Society, St. Paul

Jacobs K, Wingfield MJ, Wingfield BD (2001) Phylogenetic relationships in Leptographium based on morphological and molecular characters. Can J Bot 79:719-732. https:// doi.org/10.1139/b01-041

Jacobs K, Bergdahl DR, Wingfield MJ, Halik S, Seifert KA, Bright DE, Wingfield BD (2004) Leptographium wingfieldii introduced into North America and found associated with exotic Tomicus piniperda and native bark beetles. Mycol Res 108:411-418. https://doi.org/10.1017/ S0953756204009748

Jacobs K, Eckhardt LG, Wingfield MJ (2006) Leptographium profanum sp. nov., a new species from hardwood roots in North America. Can J Bot 84:759-766. https://doi.org/10. 1139/b06-030

Jankowiak R, Strzałka B, Bilański P, Linnakoski R, Aas T, Solheim H, Groszek M, de Beer ZW (2017) Two new Leptographium spp. reveal an emerging complex of hardwood-infecting species in the Ophiostomatales. Antonie Van Leeuwenhoek 110:1537-1553. https://doi.org/10. 1007/s10482-017-0905-8

Juzwik J, Harrington TC, McDonald WL (2008) The origin of Ceratocystis fagacearum, the Oak wilt fungus. Annu Rev Phytopathol 46:13-26

Kamgan Nkuekam G, Jacobs K, De Beer ZW, Wingfield MJ, Roux J (2008) Ceratocystis and Ophiostoma species including three new taxa, associated with wounds on native South African trees. Fungal Divers 29:37-59

Kamgan Nkuekam G, Solheim H, De Beer ZW, Grobbelaar C, Jacobs K, Wingfield MJ, Roux J (2010) Ophiostoma species, including Ophiostoma borealis sp. nov., infecting wounds of native broad-leaved trees in Norway. Cryptogam Mycol 31:285-303

Kamgan Nkuekam G, De Beer ZW, Wingfield MJ, Mohammed C, Carnegie AJ, Pegg GS, Roux J (2011a) Ophiostoma species (Ophiostomatales, Ascomycota), including two new taxa on eucalypts in Australia. Aust J Bot 59:283-297

Kamgan Nkuekam G, De Beer ZW, Wingfield MJ, Mohammed C, Carnegie AJ, Pegg GS, Roux J (2011b) Ophiostoma species (Ophiostomatales, Ascomycota), including two new taxa on eucalypts in Australia. Aust J Bot 59:283-297

Kamgan Nkuekam G, Wingfield MJ, Mohammed C, Carnegie AJ, Pegg GS, Roux J (2012) Ceratocystis species, including two new species associated with nitidulid beetles, on eucalypts in Australia. Antonie Van Leeuwenhoek 101:217-241

Katoh K, Standley DM (2013) MAFFT multiple sequence alignment software version 7: improvements in 
performance and usability. Mol Biol Evo 30:772-780. https://doi.org/10.1093/molbev/mst010

Klepzig KD, Six DL (2004) Bark beetle-fungal symbiosis: context dependency in complex associations. Symbiosis 37:189-205

Kornerup A, Wanscher JH (1978) Methuen hanbook of colour, 3rd edn. Eyre Methuen, London

Lagerberg T, Lundberg G, Melin E (1927) Biological and practical researches into blueing in pine and spruce. Sver Skogsv För Tidskr 25:145-272

Lim YW, Massoumi Alamouti S, Kim JJ, Lee S, Breuil C (2004) Multigene phylogenies of Ophiostoma clavigerum and closely related species from bark beetle-attacked Pinus in North America. FEMS Microbiol Lett 237:89-96

Linnakoski R, De Beer ZW, Duong TA, Niemelä P, Pappinen A, Wingfield MJ (2012) Grosmannia and Leptographium spp. associated with conifer-infesting bark beetles in Finland and Russia including Leptographium taigense sp. nov. Antonie Van Leeuwenhoek 102:375-399. https://doi.org/ 10.1007/s10482-012-9747-6

Malloch D, Blackwell M (1993) Dispersal biology of ophiostomatoid fungi. In: Wingfield MJ, Seifert KA, Webber JF (eds) Ceratocystis and Ophiostoma: taxonomy, ecology, and pathology. APS Press, St. Paul, pp 195-206

Massoumi Alamouti S, Kim JJ, Humble LM, Uzunovic A, Breuil C (2007) Ophiostomatoid fungi associated with the northern spruce engraver, Ips perturbatus, in western Canada. Antonie Van Leeuwenhoek 91:19-34

Mathiesen A (1951) Einige neue Ophiostoma-arten in Schweden. Sv Bot Tidskr 45:203-232

O’Donnell K, Cigelnik E (1997) Two divergent intragenomic rDNA ITS2 types within a monophyletic lineage of the fungus Fusarium are nonorthologous. Mol Phylogent Evol 7:103-116. https://doi.org/10.1006/mpev.1996.0376

Okada G, Seifert KA, Takematsu A, Yamaoka Y, Miyazaki S, Tubaki K (1998) A molecular phylogenetic reappraisal of the Graphium complex based on $18 \mathrm{~S}$ rDNA sequences. Can J Bot 76:1495-1506

Olchowecki A, Reid J (1974) Taxonomy of the genus Ceratocystis in Manitoba. Can J Bot 52:1675-1711

Osorio JA, De Beer ZW, Wingfield MJ, Roux J (2016) Ophiostomatoid fungi associated with mangroves in South Africa, including Ophiostoma palustre sp. nov. Antonie Van Leeuwenhoek 109:1555-1571. https://doi.org/10. 1007/s10482-016-0757-7

Paciura D, De Beer ZW, Jacobs K, Zhou XD, Ye H, Wingfield MJ (2010) Eight new Leptographium species associated with tree-infesting bark beetles in China. Persoonia 25:94-108. https://doi.org/10.3767/003158510X551097

Rambaut A, Drummond AJ (2007) Tracer v1.4. http://beast.bio. ed.ac.uk/Tracer

Robert V, Vu D, Amor AB et al (2013) MycoBank gearing up for new horizons. IMA Fungus 4:371-379. https://doi.org/ 10.5598/imafungus.2013.04.02.16
F, Huelsenbeck JP (2003) MrBayes 3: Bayesian phylogenetic inference under mixed models. Bioinformatics 19:1572-1574. https://doi.org/10.1093/bioinformatics/ btg 180

Roux J, VanWyk M, Hatting H, Wingfield MJ (2004) Ceratocystis species infecting stem wounds on Eucalyptus grandis in South Africa. Plant Pathol 53:414-421

Seifert KA, Wingfield MJ, Kendrick WB (1993) A nomenclator for described species of Ceratocystis, Ophiostoma, Ceratocystiopsis, Ceratostomella and Sphaeronaemella. In: Wingfield MJ, Seifert KA, Webber J (eds) Ceratocystis and Ophiostoma: taxonomy, ecology and pathogenicity. APS Press, St. Paul, pp 269-287

Six DL (2003) Bark beetle-fungus symbioses. In: Bourtzis K, Miller T (eds) Insect symbioses. CRS Press, Boca Raton, pp 97-114

Six DL, De Beer ZW, Duong TA, Carroll AL, Wingfield MJ (2011) Fungal associates of the lodgepole pine beetle, Dendroctonus murrayanae. Antonie Van Leeuwenhoek 100:231-244

Solheim H (1986) Species of Ophiostomataceae isolated from Picea abies infested by the bark beetle Ips typographus. Nord J Bot 6:199-207

Tamura K, Stecher G, Peterson D, Filipski A, Kumar S (2013) MEGA6: molecular evolutionary genetics analysis version 6.0. Mol Biol Evol 30:2725-2729. https://doi.org/10.1093/ molbev/mst197

Taylor JW (2011) One Fungus = One Name: DNA and fungal nomenclature twenty years after PCR. IMA Fungus 2:113-120

Upadhyay HP (1981) A monograph of Ceratocystis and Ceratocystiopsis. University of Georgia Press, Athens

White TJ, Bruns T, Lee S, Taylor J (1990) Amplification and direct sequencing of fungal ribosomal RNA genes for phylogenetics. In: Innis MA, Gelfand DH, Sninsky JJ, White TJ (eds) PCR protocols: a guide to methods and applications. Academic Press, New York, pp 315-322

Wingfield MJ, Kemp GHJ (1993) Diseases of Pines, Eucalyptus and Wattles. In: Van der Sidje HA (ed) South African forestry handbook. The South African Association of Forestry, Pretoria, pp 231-248

Wood SL, Bright DE (1992) A catalog of Scolytidae and Platypodiae (Coleoptera), Part 2. Taxonomic index. Great Basin Nat Mem 13:1-1553

Wright EF, Cain RF (1961) New species of the genus Ceratocystis. Can J Bot 39:1215-1230

Yin M, Duong TA, Wingfield MJ, Zhou XD, De Beer ZW (2015) Taxonomy and phylogeny of the Leptographium procerum complex, including $L$. sinense sp. nov. and $L$. longiconidiophorum sp. nov. Antonie Van Leeuwenhoek 107:547-563. https://doi.org/10.1007/s10482-014-0351-9

Zipfel RD, De Beer ZW, Jacobs K, Wingfield BD, Wingfield MJ (2006) Multi-gene phylogenies define Ceratocystiopsis and Grosmannia distinct from Ophiostoma. Stud Mycol 55:75-97. https://doi.org/10.3114/sim.55.1.133 